Article

\title{
Novel Ensemble Approach of Deep Learning Neural Network (DLNN) Model and Particle Swarm Optimization (PSO) Algorithm for Prediction of Gully Erosion Susceptibility
}

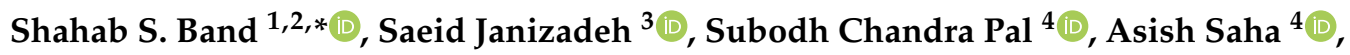 \\ Rabin Chakrabortty ${ }^{4}$, Manouchehr Shokri ${ }^{5}$ and Amirhosein Mosavi ${ }^{6,7}$ \\ 1 Institute of Research and Development, Duy Tan University, Da Nang 550000, Vietnam \\ 2 Future Technology Research Center, National Yunlin University of Science and Technology, \\ 123 University Road, Section 3, Douliou, Yunlin 64002, Taiwan \\ 3 Department of Watershed Management Engineering and Sciences, Faculty in Natural Resources and Marine \\ Science, Tarbiat Modares University, 14115-111 Tehran, Iran; janizadehsaeid@modares.ac.ir \\ 4 Department of Geography, The University of Burdwan, West Bengal, Burdwan 713104, India; \\ scpal@geo.buruniv.ac.in (S.C.P.); asishsaha01@gmail.com (A.S.); rabingeo8@gmail.com (R.C.) \\ 5 Institute of Structural Mechanics, Bauhaus Universität Weimar, 99423 Weimar, Germany; \\ manouchehr.shokri@uni-weimar.de \\ 6 Environmental Quality, Atmospheric Science and Climate Change Research Group, \\ Ton Duc ThangUniversity, Ho Chi Minh City 700000, Vietnam; amirhosein.mosavi@tdtu.edu.vn \\ 7 Faculty of Environment and Labour Safety, Ton Duc Thang University, Ho Chi Minh City 700000, Vietnam \\ * Correspondence: shamshirbandshahaboddin@duytan.edu.vn
}

Received: 11 August 2020; Accepted: 24 September 2020; Published: 30 September 2020

Abstract: This study aims to evaluate a new approach in modeling gully erosion susceptibility (GES) based on a deep learning neural network (DLNN) model and an ensemble particle swarm optimization (PSO) algorithm with DLNN (PSO-DLNN), comparing these approaches with common artificial neural network (ANN) and support vector machine (SVM) models in Shirahan watershed, Iran. For this purpose, 13 independent variables affecting GES in the study area, namely, altitude, slope, aspect, plan curvature, profile curvature, drainage density, distance from a river, land use, soil, lithology, rainfall, stream power index (SPI), and topographic wetness index (TWI), were prepared. A total of 132 gully erosion locations were identified during field visits. To implement the proposed model, the dataset was divided into the two categories of training $(70 \%)$ and testing (30\%). The results indicate that the area under the curve (AUC) value from receiver operating characteristic (ROC) considering the testing datasets of PSO-DLNN is 0.89, which indicates superb accuracy. The rest of the models are associated with optimal accuracy and have similar results to the PSO-DLNN model; the AUC values from ROC of DLNN, SVM, and ANN for the testing datasets are $0.87,0.85$, and 0.84 , respectively. The efficiency of the proposed model in terms of prediction of GES was increased. Therefore, it can be concluded that the DLNN model and its ensemble with the PSO algorithm can be used as a novel and practical method to predict gully erosion susceptibility, which can help planners and managers to manage and reduce the risk of this phenomenon.

Keywords: gully erosion susceptibility; deep learning neural network; DLNN; particle swarm optimization; PSO; geohazard; geoinformatics; ensemble model; erosion; hazard map; spatial model; deep learning; natural hazard; extreme events 


\section{Introduction}

Biodiversity in a given area depends on, to a large extent, and supports the most vital natural resources in the soil, which also contribute to the provision of basic human needs such as food, fresh air, and clean water [1]. Therefore, human survival largely depends on the soil component. Soil erosion in the form of gully erosion is a serious global problem, and it continues to pose a threat to soil and water resources, particularly in arid and semi-arid regions of Iran [2,3]. Among the several types of water-induced erosion, gully erosion is a more intense form of soil erosion [4] and is one of the most complex geomorphic phenomena on the Earth's surface [5]. Such erosional activities also change the shape of the Earth's landform and produce a rugged topography, which is not suitable for production activities, construction of communication networks, etc. Thus, water-induced soil erosion is the main cause of the destruction of agricultural land, vegetation, and ecosystems, and is ultimately responsible for a devastating land degradation phenomenon. It has been estimated that the annual rate of global soil erosion is approximately 75 billion tons [6]. From an international perspective, Iran ranks second in terms of land losses, and the annual rate of soil erosion is close to 2 to 2.5 billion tons [7]. It has also been predicted that Iran's average soil erosion rate is 30-32 tons/ha/year, which is 4.3 times the world average (Food and Agriculture Organization of the United Nations (FAO), 1984). In Iran, soil erosion has been estimated to have caused more than USD 1 billion in economic losses (FAO, 2015) and is a national threat [8]. Thus, it is necessary to protect the soil from erosion and to avoid the phenomenon of land degradation worldwide. The main cause of intensive water-related gully erosion and its development is a long hot/dry season followed by an extremely wet period. Therefore, extreme rainfall causes a large amount of surface runoff over the infiltration capacity and easily transports loose soil particles onto the downward slope. Thus, soil erosion related to water in Iran is a major barrier to sustainable development in the areas of agriculture, watershed management, and other activities related to resource development [9]. Hence, the preparation of a gully erosion susceptibility (GES) map is essential for sustainable management, development, and protection of the most vital natural resource on the Earth's surface, i.e., soil, from intense gully formation and development.

Before preparing a GES map, it is necessary to understand the definition of a gully, its morphological characteristics, causes of occurrences, conditioning factors, and its ultimate impact on the land surface. A gully can be defined as a deep, narrow channel with a depth of more than $30 \mathrm{~cm}$, usually produced by surface and subsurface runoff after a heavy downpour with a temporary flow of water within that channel [8]. Gullies generally transport a large amount of sediment from the high slope or plateau of the unprotected soil surface, i.e., areas with less vegetation, to the down-slope areas of a watershed. It is also a fact that within $5 \%$ of the area of a watershed, between $10 \%$ and $94 \%$ of sediment moves downwards due to gully erosion [10]. According to Poesen [11], different factors affect gully erosion, and these factors are classified into two categories: (a) anthropogenic activities such as excessive use of farm land, overgrazing, unplanned manner of road construction, deforestation, etc., and (b) physical conditions such as topography, climate, vegetation cover, mineral composition in the soil, etc. Depending upon the depth, gullies are classified into three types, i.e., if the depth is $<0.3 \mathrm{~m}$ then it is called a grove, if the depth is between 0.3 and $2 \mathrm{~m}$ it is called a shallow gully, and if the depth is $>2 \mathrm{~m}$ it is known as a deep gully [12]. Intensive gully erosion causes many environmental problems, such as accumulation of sediment in rivers and devastating floods, as it removes fertile soils, which has a serious impact on agricultural fields, minimizes soil water storage capacity, destroys roads, and ultimately produces badlands [13-15]. It is also a well-known fact that similar factors are not responsible for the occurrence of gullies in several places in the world. Gullies are generally formed and developed based on the local topographical, climatological, and hydrological characteristics. Therefore, different gully-prone areas and associated factors need to be identified by mapping the gully erosion susceptibility. Not only this, but a suitable prediction model along with the identification of respective favorable gully erosion conditioning factors (GECFs) are also essential for an unbiased prediction result. Several methods such as statistical, machine learning (ML), and ensemble algorithms have been used for mapping GES, with the combination of remote sensing and geographic information systems. Thus, GES mapping, using 
the aforementioned newly developed methods, can help land use planners to maintain soil and water resources sustainably and accurately. Furthermore, the potential of the respective region will ultimately increase when suitable measures are taken.

In recent times, ML algorithms have been widely used for the spatial prediction of several natural hazards such as flooding, landslides [16], wildfires [17], etc. Several researchers throughout the world have carried out GES mapping by using statistical as well as ML algorithms. Some of the widely used statistical methods to predict GES mapping are frequency ratio [7], logistic regression [18], weight of evidence (WoE) [19], index of entropy (IoE) [5], etc. Besides statistical methods, different ML algorithms have also been widely used to predict GES mapping such as artificial neural network (ANN) [20], support vector machine (SVM) [20], random forest (RF) (Hosseinalizadeh et al. 2019), multi-layer perception (MLPC) approaches [21], classification and regression tree (CART) [22], boosted regression tree (BRT) [7], particle swarm optimization (PSO) [23], multi-variate adaptive regression spline (MARS) [5], and maximum entropy [24]. Ensemble models have also been widely used for their novelties and capabilities in the comprehensive analysis of GES mapping [25]. Ensemble models are applied for high precision and predictive analysis of any kind of natural hazard susceptibility mapping. In other words, the presentation of an ML model is significantly enhanced by using an ensemble model. Along with machine learning models, different ensemble models have also been used for gully erosion modeling [20].

In very recent times, the deep neural learning network (DLNN) is a striking ML algorithm and has been widely used by several research groups. This method was proposed for the first time in 2006 and includes different key features of ML as well as artificial intelligence (AI). The DLNN algorithm consists of fully convolutional neural networks (CNNs), deep belief networks (DBNs), stacked auto-encoder (SAE) networks, etc. [26]. In addition to this, the Adaptive moment estimation (Adam) and Rectified Linear Unit (ReLU) algorithms were used for training and activation purposes in every learning unit of a DLNN model [27]. Generally, the DLNN algorithm has been used in different fields such as feature extraction and transformation through supervised and unsupervised processes, recognition of patterns, and classification [28]. On the other hand, the particle swarm optimization (PSO) algorithm is an extended part of AI and an amalgamation of the conventional ML techniques. The PSO algorithm is based on swarm intelligence, and it is straightforward with efficient universal optimization techniques [26]. PSO is used for the feature selection of a dataset through optimization techniques.

Deep learning (DL) and traditional ML algorithms have some basic differences, namely that the DL algorithm needs a big data size to perform and analyze successfully, and in the case of ML algorithms, they are performed in a certain way according to established rules. The DL algorithm requires a lot more matrix operation functions than the ML algorithm does to perform well [29]. In the case of the problem-solving method, the DL algorithm is done through end-to-end problem solving, whereas in the case of ML, it breaks down into multiple sub-problems. Therefore, the DL algorithm is much better than the traditional ML algorithm for mapping the GES zone. Thus, the greatest advantage of using the DLNN algorithm is that this model is capable of building a high-level feature from a raw dataset scientifically, and is also capable of delivering forecasting results using time series data. In addition to this, DLNN consists of a different topology than the general neural network of a single hidden layer; thus, more than one hidden layer is present in this algorithm. For this reason, in various research areas, the DL algorithm has better performance than the conventional ML algorithm [30]. In the case of PSO, it is also used to conquer the problems of local optima through feature selection methods. PSO determines the quality of a dataset's features through a multi-objective fitness function [31]. As a result, the output layer of different hidden layers is optimized by the PSO algorithm to obtain more accurate predictions [32].

Therefore, the present research work has been carried out to predict GES mapping in Shirahan watershed, which is tremendously affected by water-induced gully erosion. To fulfill our research objective, we used thirteen suitable GECFs with a total of 132 gully head-cut points (each for gully and non-gully), splitting them into a 70/30 ratio for training and testing datasets. Furthermore, to creatively model the GES mapping, we used a DL as well as a conventional ML algorithm. In this study, we used DLNN, PSO, artificial neural network (ANN), and support vector machine (SVM) algorithms. 
According to several literature surveys on GES mapping and the best of our knowledge, it was noticed that the DLNN model has not been used in GES assessment so far; thus, this study was carried out to investigate the potential application of the DLNN model for GES mapping. In this study, an attempt was also made to use the PSO algorithm to optimize the parameters of the deep learning model (DLNN) in the training phase and to introduce a new approach of an ensemble of PSO and DLNN in GES modeling. Not only this, but a comparison was also made between the ensemble of PSO-DLNN and conventional ANN and SVM algorithms. Thus, the application of DL and the PSO-DLNN ensemble approach for GES mapping is the novelty in this research study, as the result of this approach improved the prediction accuracy compared with any single ML algorithm. Thereafter, all of the output results were validated through sensitivity (SST), specificity (SPF), positive predictive values (PPV), negative predictive values (NPV), receiver operating characteristic-area under the curve (ROC-AUC), likelihood ratio, F-measures, and maximum probability of correct decision (MPCD) statistical analyses. Thus, the DL and PSO-DLNN ensemble methods can help to forecast and control the creation and development of gullies in Shirahan watershed, Iran.

\section{Materials and Methods}

\subsection{Description of the Study Area}

Shirahan watershed is located at a longtitude of $20^{\circ} 57^{\prime}$ to $28^{\circ} 57^{\prime}$ and a latitude of $51^{\circ} 25^{\prime}$ to $51^{\circ}$ $26^{\prime}$, in the central part of Hormozgan Province and to the south of Bandar-e Jask city (Figure 1). The area of the watershed is $138 \mathrm{~km}^{2}$, the minimum height of the area is $2 \mathrm{~m}$, and the maximum height is $214 \mathrm{~m}$ above sea level. According to statistics recorded at Jask Synoptic Station over a period of 28 years (1989-2017), precipitation in this region is very heavy, and more than $50 \%$ of it occurs in winter. According to the information of the above station, the average annual rainfall is $116.75 \mathrm{~mm}$, the maximum annual rainfall is $320 \mathrm{~mm}$, and the minimum is $27 \mathrm{~mm}$. The climate of the region is hot and dry according to the Ambregeh method and hot/dry based on the Domarten method. Soil texture is generally silt/loam and loam. In this area, the percentage of clay increases with increasing depth. However, changes in the percentage of sand and silt do not follow a specific trend and have high fluctuations. In this area, the horizon of $75-75 \mathrm{~cm}$ has the highest degree of salinity (Table 1). Pictures of ditch erosion are shown in Figure 2. To study the geometric features and physical and chemical properties of the soil, 20 ditches were sampled in the study area. Studies showed further expansion of ditch erosion in salt marshes, which are located in the plain type. The general plan of ditches is compound, and their cross-sectional shape is trapezoidal. The average depth of ditches is $2.7 \mathrm{~m}$; the average width is $10.3 \mathrm{~m}$. Laboratory studies were used to evaluate the soil characteristics of the gullies of Shirahan watershed. Meanwhile, soil samples were taken from the soil surface to a depth of $290 \mathrm{~cm}$ and sent to the laboratory of Bandar Abbas Agricultural and Natural Resources Research Center for soil testing. Laboratory results showed that the soil texture in the area up to the depth under study is loose. The physical and chemical properties of the soil at 6 different soil depths are shown for the ditches studied in Table 1. Some field photographs of a gully in the present study area of Shirahan watershed are shown in Figure 2.

Table 1. Physical and chemical properties of soil in the gullies of Shirahan watershed.

\begin{tabular}{|c|c|c|c|c|c|c|}
\hline \multirow{2}{*}{ Features } & \multicolumn{6}{|c|}{ Soil Depth $(\mathrm{cm})$} \\
\hline & $0-30$ & $30-75$ & 75-130 & 130-180 & $18-250$ & $250-290$ \\
\hline $\mathrm{PH}$ & 8.06 & 7.59 & 8.19 & 7.69 & 8.32 & 7.38 \\
\hline $\mathrm{EC}(\mathrm{mmhos} / \mathrm{cm})$ & 2.26 & 34.6 & 2.23 & 33.9 & 2.4 & 33.2 \\
\hline $\mathrm{Na}(\mathrm{Meq} / \mathrm{lit})$ & 8.82 & 285 & 8.87 & 285 & 8.8 & 248 \\
\hline $\mathrm{Ca}+\mathrm{Mg}(\mathrm{Meq} / \mathrm{lit})$ & 13.6 & 64.4 & 13.7 & 62.4 & 13.4 & 63.2 \\
\hline SAR & 3.4 & 50.2 & 3.4 & 50.2 & 3.4 & 50.2 \\
\hline Clay (\%) & 24 & 26 & 26 & 27 & 29 & 28 \\
\hline Silt (\%) & 58 & 30 & 60 & 32 & 56 & 30 \\
\hline Sand $(\%)$ & 18 & 44 & 14 & 41 & 15 & 42 \\
\hline Soil texture & Silt-Loam & Loam & Silt-Loam & Loam/clay-loam & Silty-Clay-Loam & Clay-Loam \\
\hline
\end{tabular}




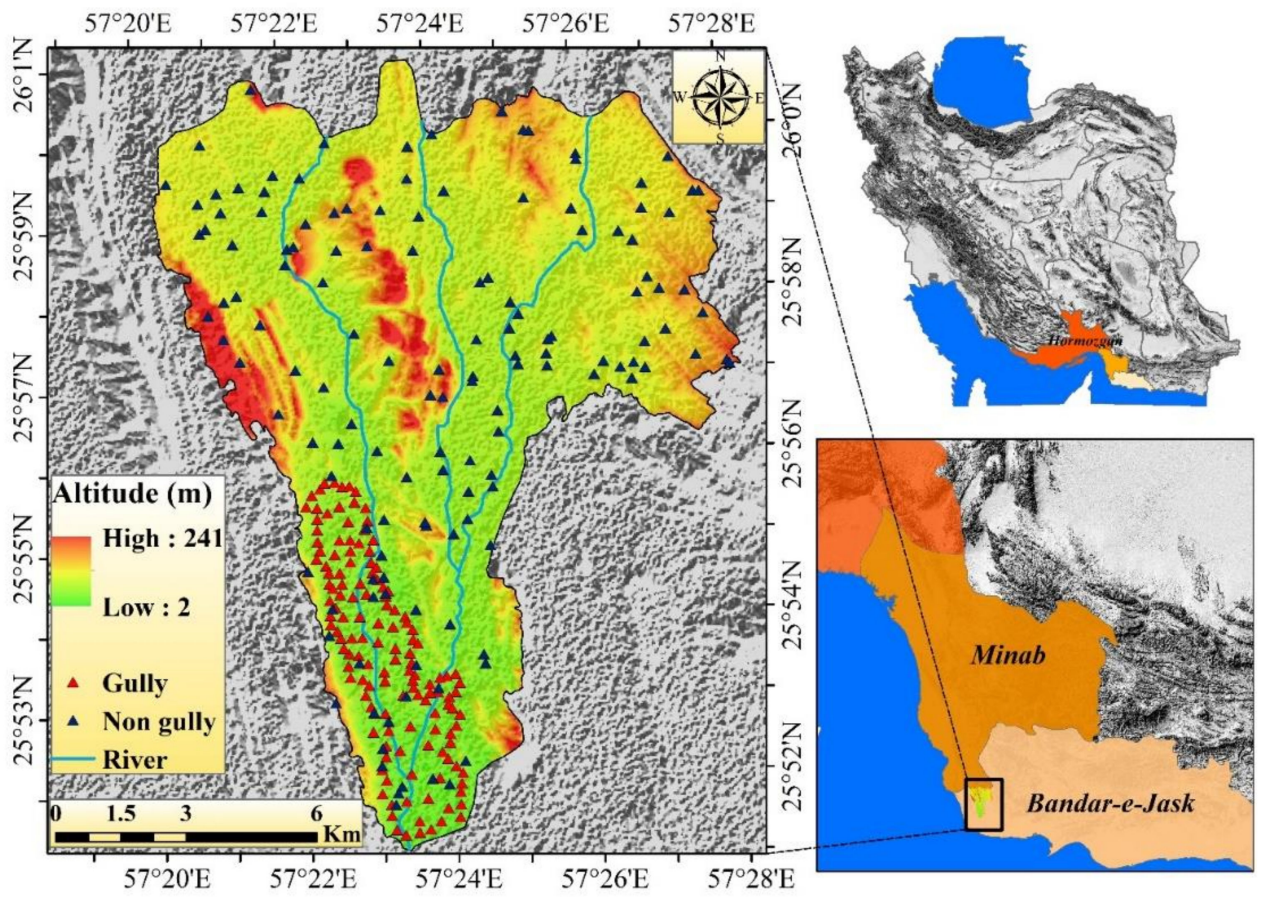

Figure 1. Location of the study area in Iran.

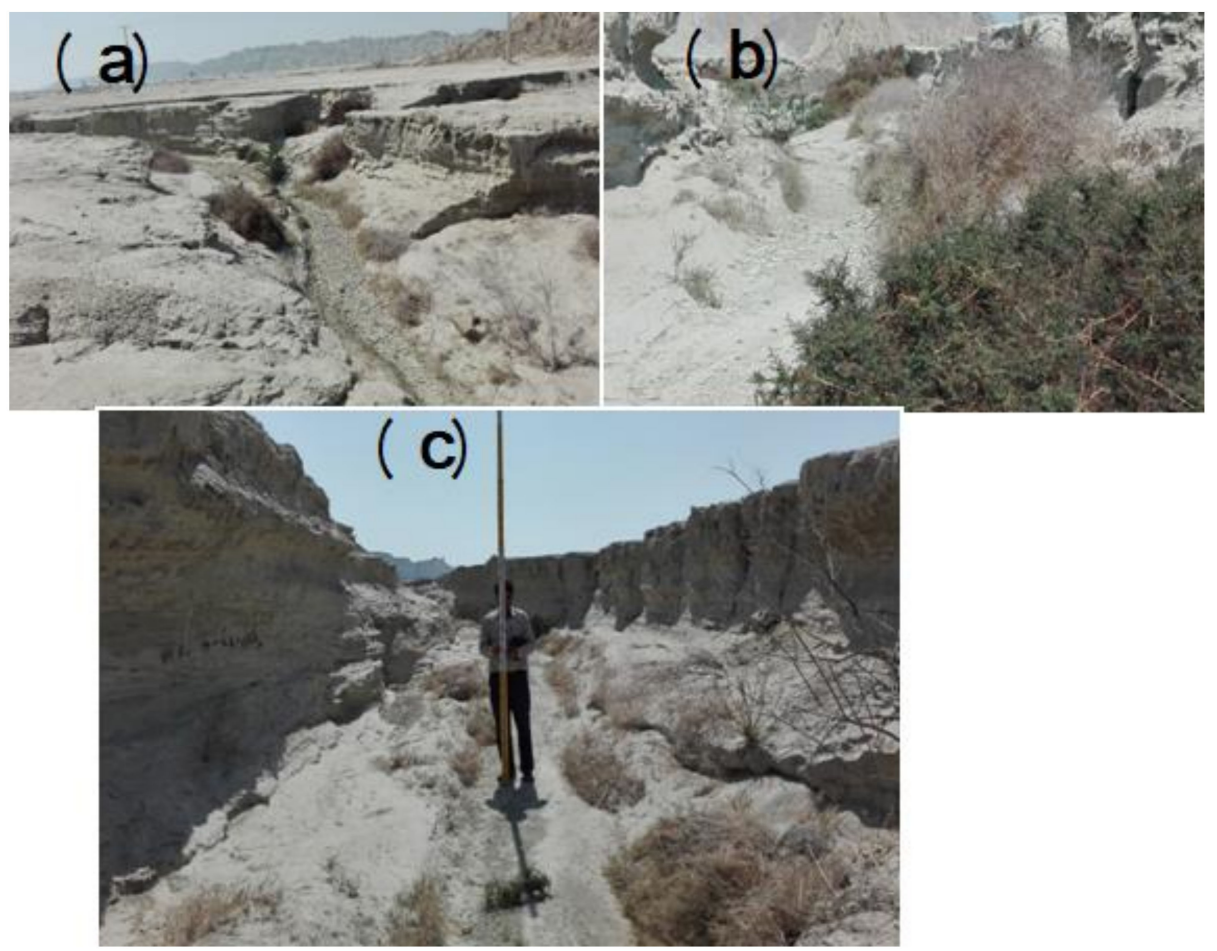

Figure 2. Images of gully erosion in Shirahan watershed: (a) head-cut gully; (b) gully erosion in salt land area; (c) measurement of gully morphometric properties.

\subsection{Methodology}

The methodological approach used in this research work is discussed in the following section, and the respective flowchart is presented in Figure 3. 


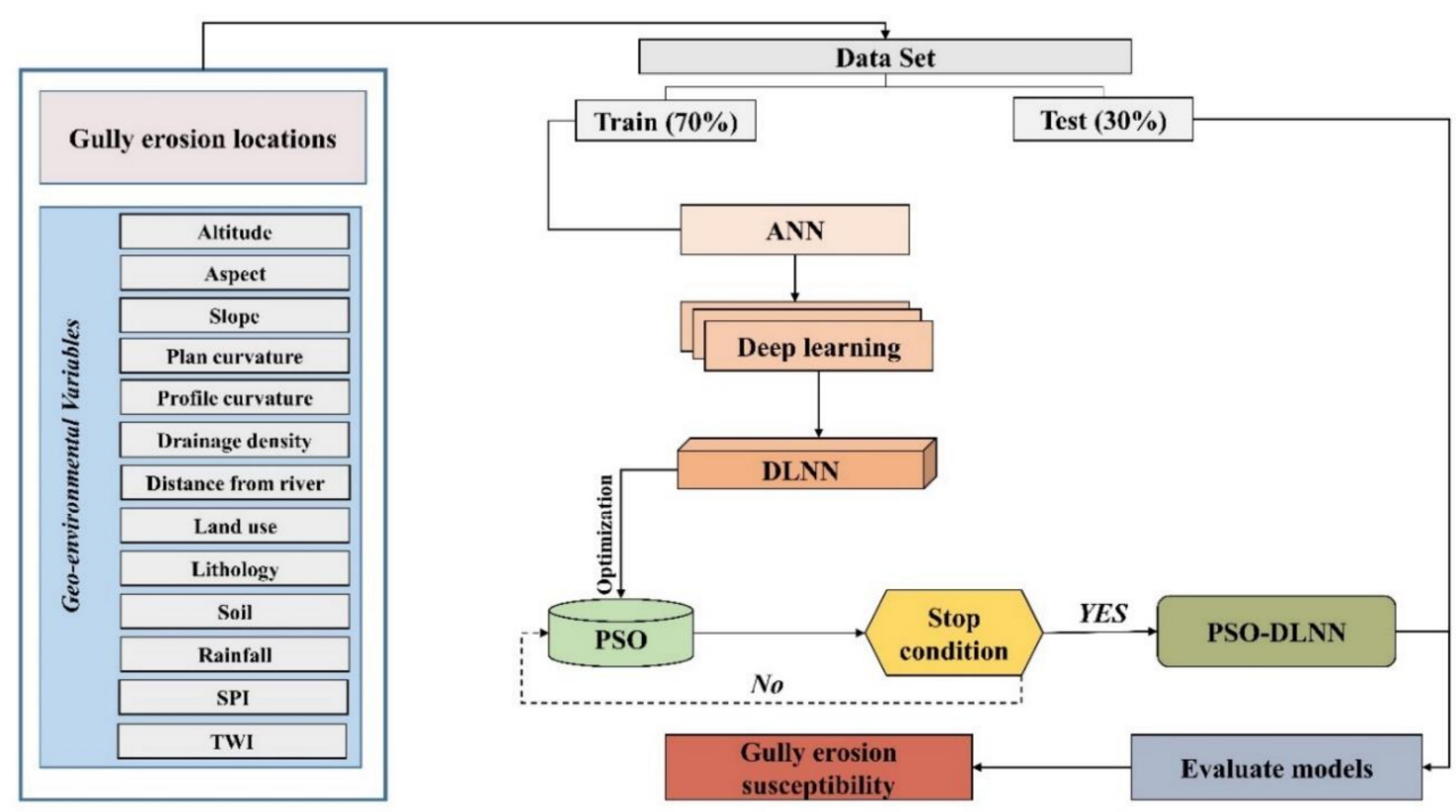

Figure 3. Methodological flowchart of particle swarm optimization (PSO)-deep learning neural network (DLNN) in gully erosion susceptibility.

Firstly, a gully erosion inventory map was prepared based on the 132 gully head-cut points (with gully and non-gully for each). These gully head-cut points were identified based on field visits and information from the Administration of Natural Resources of Hormozgan Province. Along with this, the non-gully points were randomly selected throughout the basin area with the help of the geographic information system (GIS) environment. Besides this, a total of thirteen (13) of gully erosion conditioning factors (GECFs), i.e., target variables, were considered for modeling GES based on the local topographical and climatological factors in association with several literature studies. These GECFs are altitude, aspect, slope, plan curvature, profile curvature, drainage density (DD), distance from a river, land use, lithology, soil, rainfall, stream power index (SPI), and topographic wetness index (TWI). Thereafter, multi-collinearity analysis of variance inflation factor (VIF) and tolerance (TOL) techniques were used among different GECFs to determine the linear relationship among the variables. Afterwards, modeling of GES was done by using SVM, ANN, and DLNN machine learning (ML) algorithms, and a novel ensemble of PSO-DLNN. Lastly, the results of the several GES models were validated through a ROC curve analysis to assess their accuracy.

The methodology of the present research work was carried out to solve classification problems using the aforementioned ML and DL algorithms for prediction GES mapping. Besides this, the several target variables used in this study are a combination of logical, discrete, and continuous variables. During the processing of all of these variables' data, it was recognized among the variables whether each one was a logical, discrete, or continuous one, in the SPSS 25 statistical software designed by International Business Machines (IBM), New York, USA. In this study, we also analyze affected areas of gully erosion susceptible zone, by using the presence of gully head-cut points, and we also compute the GES zones based on the gully/non-gully head-cut points along with several conditioning factors for sustainable management of the gully-affected areas.

\subsection{Dataset Preparation for Spatial Modeling}

In this study, a gully erosion inventory map (Figure 1) was prepared based on field visits and information from the Administration of Natural Resources of Hormozgan Province, which resulted in a total of 132 gully points. To determine the non-gully points, GIS software was used and 132 points were randomly selected. The digital elevation model (DEM) map was obtained with a pixel size of $12.5 \mathrm{~m}$ 
from the Advance Land Observatin Satellite/Phased Array type L-band Synthetic Aperture Radar (ALOSPALSAR) sensor. The topographical factors such as slope map, direction curve, plan curvature, and profile curvature were prepared based on DEM in the GIS environment. The map of the distance from a river based on the Euclidean extension was obtained in GIS software. A drainage density map was prepared using a line density extension. SAGAGIS software was used to map TWI and SPI. The soil type map of the region was obtained based on the map prepared by the Administration of Natural Resources of Hormozgan Province. The lithological map was prepared based on the geological map of 1:100,000 of the country's mapping organization. Land use maps were prepared based on Landsat satellite images and Operational Land Imager (OLI) measurement, using the maximum probability algorithm in the ENVI software environment. The precipitation map of the constituency was prepared from the statistics of 4 climatological factors in the constituency over a period of 28 years (1989-2017) and based on the inverse distance weighting (IDW) interpolation method. Details about the data sources used in this research work are presented in Table 2.

Table 2. Details about the data sources of several factors used in this study.

\begin{tabular}{|c|c|c|c|}
\hline Parameters & Data Source & $\begin{array}{l}\text { Time } \\
\text { (Year) }\end{array}$ & $\begin{array}{c}\text { Spatial } \\
\text { Resolution/Scale }\end{array}$ \\
\hline $\begin{array}{l}\text { Altitude, slope, aspect, profile } \\
\text { curvature, plan curvature, drainage } \\
\text { density (DD), distance from river, } \\
\text { stream power index (SPI), } \\
\text { topographic wetness index (TWI) }\end{array}$ & $\begin{array}{c}\text { ALOS PALSAR DEM } \\
\text { (Alaska Satellite Facility) }\end{array}$ & 2012 & $12.5 \mathrm{~m}$ \\
\hline Rainfall & $\begin{array}{l}\text { Iran Meteorological Organization (IMO) } \\
\text { (http://www.weather.ir/) }\end{array}$ & $\begin{array}{l}1989 \text { to } \\
2017\end{array}$ & \\
\hline Lithology & $\begin{array}{l}\text { Geological Survey of Iran (GSI) } \\
\text { (http://www.gsi.ir/) }\end{array}$ & 2019 & $1: 1,000,000$ \\
\hline Land use & Landsat OLI 8 satellite image (USGS) & 2019 & $30 \mathrm{~m}$ \\
\hline Soil texture & $\begin{array}{l}\text { Soil and Water Research Institute } \\
\text { (http://www.iran.swri.com) }\end{array}$ & 2019 & $1: 1,000,000$ \\
\hline
\end{tabular}

A total of 13 GECFs were selected for GES mapping in this research work, namely, altitude, aspect, slope, plan curvature, profile curvature, drainage density (DD), distance from a river, land use, lithology, soil, rainfall, stream power index (SPI), and topographic wetness index (TWI) (Figure 4a-m).

The altitude of the present study area ranges from 2 to $241 \mathrm{~m}$ (Figure 4a). Altitude is an important factor for the occurrence of gullies due to influences on rainfall-runoff processes, and it is largely employed in GES mapping [3]. Slope aspect indirectly affects the occurrence of gully erosion as it affects the reception of sunlight, vegetation cover, and humidity [33]. Here, the slope aspect map has nine classes, i.e., flat, N, NE, E, SE, S, SW, W, and NW (Figure 4b). Slope angle influences the pattern of runoff and infiltration rate. Therefore, depending on the slope, the erosional rate also varies from place to place, i.e., high slope areas have high erosion rates and vice versa. The slope map is shown in Figure $4 \mathrm{c}$, and the value ranges from $0 \%$ to $362.74 \%$. In a particular direction, the rate of gradient change is known as curvature, within which, plan and profile curvature generally represent the topographic characteristics of an area. The value of plan curvature ranges from -30.27 to 24.08 (Figure $4 \mathrm{~d}$ ) and profile curvature from -29.63 to 30.93 (Figure 4e). DD directly impacts occurrences of gully erosion. Horton's (1932) following equation was used to calculate DD. In this study, the DD value ranges from 0 to $2.27 \mathrm{~km} / \mathrm{km}^{2}$ (Figure $4 \mathrm{f}$ ).

$$
D D=\frac{\sum_{i=1}^{n} S_{i}}{a}
$$

where $\sum_{i=1}^{n} S_{i}$ is the length of drainage in $\mathrm{km}$, and ' $a$ ' indicates the total area of the drainage basin in $\mathrm{km}^{2}$.

Distance from a river also influences occurrences of gully erosion as it greatly impacts the wetting capacity of surface area and associated erosional activities. The value of the distance from a river ranges from 0 to $4680.17 \mathrm{~m}$ (Figure $4 \mathrm{~g}$ ). The land use type of the area is very much responsible for the occurrence of gully erosion. Bare or less vegetated areas of the land surface are highly prone to gully 
erosion. In this study, four types of land use were recognized, i.e., agricultural land, rangeland, rock surface, and salt land (Figure $4 \mathrm{~h}$ ). The lithological factor of an area is highly responsible for erosional activities such as the development of a gully [34]. The present study area of Shirahan watershed consists of five types of lithological unit (Figure 4i). The soil map of the study area is shown in Figure $4 \mathbf{j}$, and it is classified into two categories, i.e., entisols/aridisols and badlands. Rainfall is the most important factor for the formation of a gully and its development, mainly in the arid and semi-arid areas. High-intensity rainfall with short duration is the most devastating for gullies. Here, 28 years of rainfall data have been used to prepare a rainfall map (Figure 4k), and it ranges from 125 to $175 \mathrm{~mm}$. SPI indicates the stream's erosional capacity [25]. SPI value was calculated by using the following equations, and the value ranges from 0 to 2.625 in this research work (Figure 4l).

$$
S P I=A s \times \tan \beta
$$

where $A_{S}$ represents the upslope contributing area, and $\beta$ represents the slope angle.
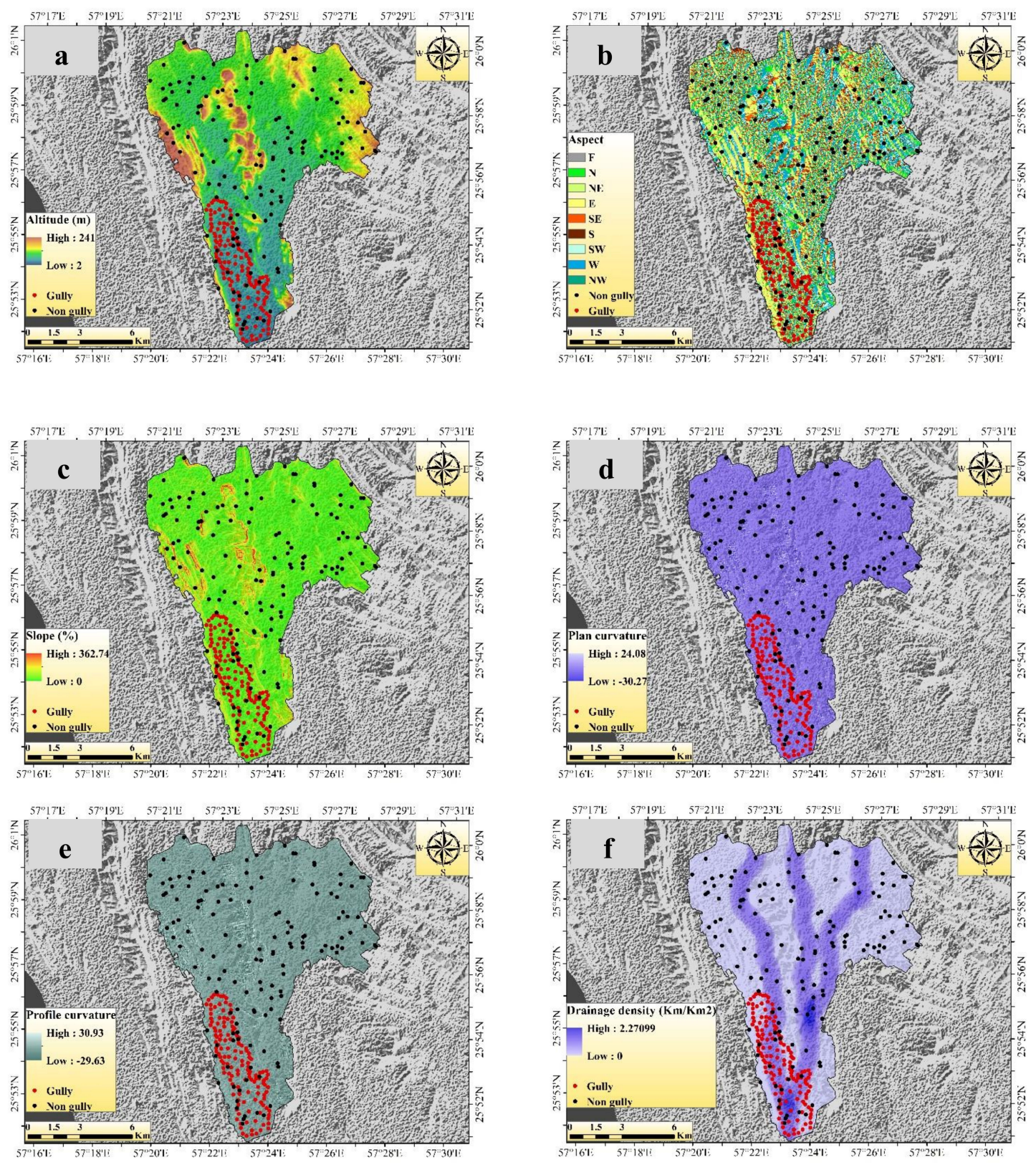

Figure 4. Cont. 

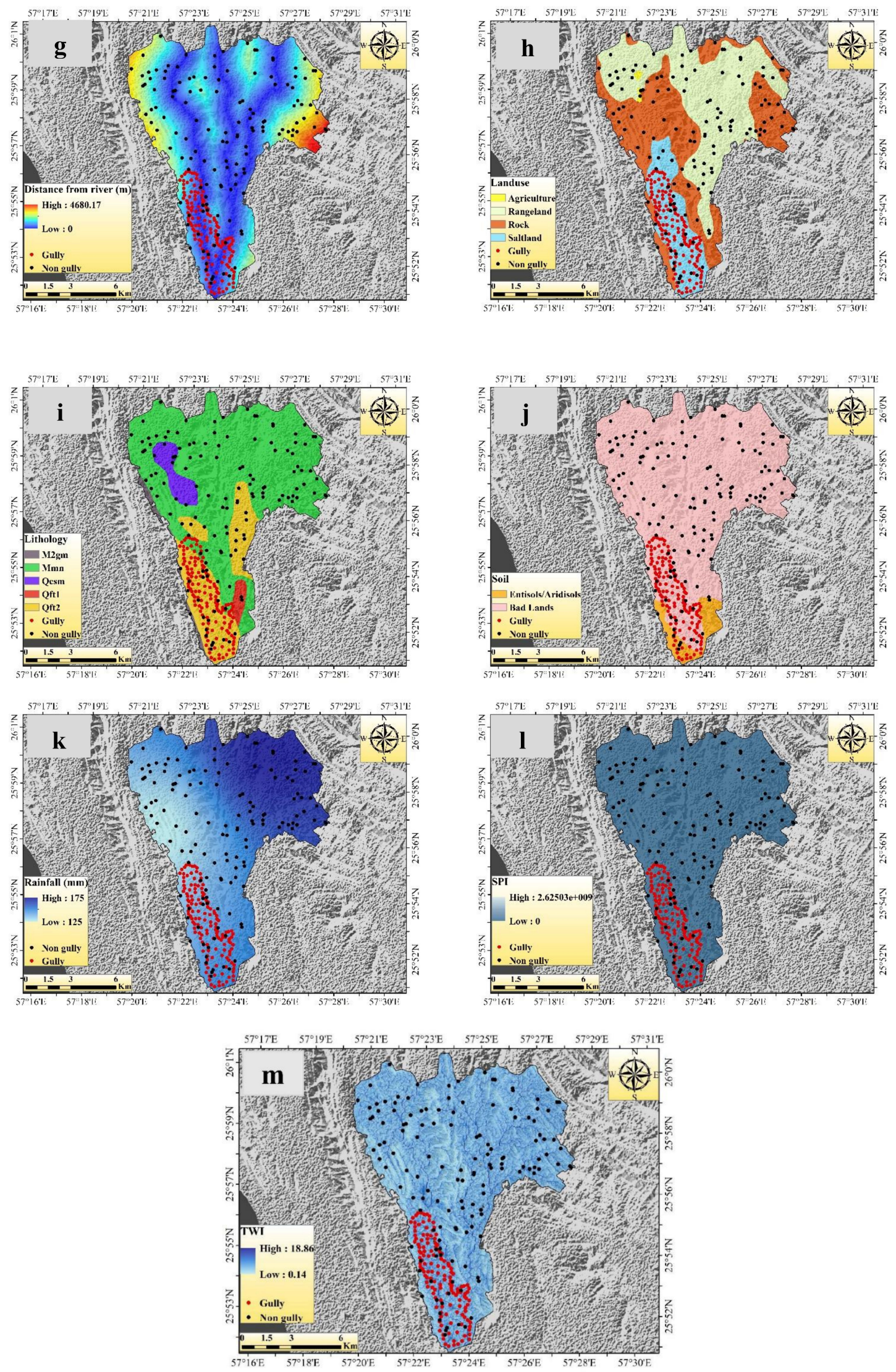

Figure 4. Gully erosion conditioning factors: (a) altitude, (b) slope, (c) aspect, (d) plan curvature, (e) profile curvature, (f) drainage density, (g) distance from a river, (h) land use, (i) soil, (j) lithology, (k) rainfall, (1) stream power index (SPI), and (m) topographic wetness index (TWI). 
TWI determines transport capacity along with flow velocity [7], and it is an essential factor for identifying gully erosion-prone areas [35]. The following equation was used to calculate TWI value, and it ranges from 0.14 to 18.86 (Figure $4 \mathrm{~m}$ ).

$$
T W I=\operatorname{In}\left(\frac{A_{s}}{\tan \beta}\right)
$$

where $A_{s}$ represents the area of a catchment in $\mathrm{m}^{2}$, and $\beta$ represents the gradient of the slope in radians.

\subsection{Multi-Collinearity Analysis}

Multi-collinearity analysis always gives the perfect outcome to evaluate the linear dependency of different geo-environmental factors in an ML model $[15,36]$. It is a statistical analysis and is able to find two variables of high correlation in a multiple regression study. Thus, it is very much essential to analyze the multi-collinearity of a model to obtain better results through removing the high multi-collinearity factors and minimizing the bias of the model [37]. Several researchers throughout the world have used multi-collinearity analysis in different fields such as GES mapping [21], floods [38], and landslide susceptibility mapping [39]. Multi-collinearity can be analyzed through variance inflation factor (VIF) and tolerance (TOL) [40]. As a general rule, if the TOL value is $<0.10$ or 0.20 and the VIF value is $>5$ or 10 , then the result indicates high multi-collinearity among the variables [41]. The following equations were used to calculate TOL and VIF in a dataset:

$$
\begin{gathered}
\text { TOL }=1-R_{j}^{2} \\
V I F=\frac{1}{T O L}
\end{gathered}
$$

where $R_{j}^{2}$ indicates the regression value of $j$ on other different variables in a dataset.

\subsection{Machine Learning Method Used in Modeling the Gully Erosion}

\subsubsection{Support Vector Machine (SVM)}

SVM is a very popular machine learning algorithm and was introduced by Vapnik and Chervonenkis in 1963. Several researchers throughout the world have used this machine learning classifier in the field of predicting different natural hazards such as in GES mapping [42], landslide prediction [43], flood susceptibility mapping [44], etc. SVM is implemented to solve regression analysis and multi-faceted classifier problems [45]. Vapnik [46] stated that SVM is based on the principle of structural risk minimization and statistical learning, and it is a supervised machine learning model. SVM is very much effective to reduce the error of the complexity of a linear computation and model overfitting [47]. Two types of statistically induced problems are engaged in SVM modeling. The first one is linear separating of the hyperplane by using statistical data, and the second one is converting non-linear data into linearly separable data [48]. Generally, the data processing in SVM of a non-linear relationship is done through the kernel function [49]. In addition to this, two classes can be discretely generated in SVM modeling by an optimal hyperplane, in which one class indicated above the hyperplane is assigned as 1 and the other one, located below the hyperplane, is assigned as 0 , i.e., in this case gully erosion and non-gully erosion, respectively [50]. SVM has been developed for regression estimation, particularly paying attention to the solution of inverse problems. The novelty of the SVM model is that it has attempted to relocate the idea through kernel techniques for working out the inner products of unsupervised learning. Besides this, it can also be applied for singular components where the distribution of data is not well-defined. Therefore, a large class of functions can be applied for non-linearity mapping with high feature space by using this kernel trick. The hyperplane in an SVM can be calculated by using following equations: 


$$
\operatorname{Min} \sum_{i=1}^{n} \varphi_{i}-\frac{1}{2} \sum_{i=1}^{n} \sum_{j=1}^{n} \varphi_{i} \varphi_{j} y_{i} y_{j}\left(x_{i}, x_{j}\right)
$$

subject to

$$
\operatorname{Min} \sum_{i=1}^{n} \varphi_{i} y_{j}=0 \text { and } 0 \leq \alpha_{i} \leq \mathrm{D}
$$

where $x=x_{i}, i=1,2, \ldots n$ are input variables of the vector; $y=y_{i}, j=1,2, \ldots n$ are output variables of the vector, and $\varphi_{i}$ represents Lagrange multipliers.

Finally, the decision function of SVM can be classified as

$$
f(x)=\operatorname{sgn}\left(\sum_{i=j}^{n} y_{i} \varphi_{i} K\left(x_{i}, x_{j}\right)+a\right)
$$

where a represents a bias, which indicates the linear distance of the hyperplane from the origin, $K\left(x_{i}, x_{j}\right)$ represent kernel functions, i.e., polynomial (POL) and radial basis function (RBF), and these can be expressed as follows [51]:

$$
\begin{gathered}
K_{P O L}\left(x_{i}, x_{j}\right)=((x * y)+1)^{d} \\
K_{R B F}\left(x_{i}, x_{j}\right)=e^{-y\left\|x-x_{i}\right\|^{2}}
\end{gathered}
$$

\subsubsection{Artificial Neural Network (ANN)}

ANN is a popular machine learning algorithm that simulates the neural networks of a human brain and can work in a specific way [52,53]. It is used to analyze and predict non-linear statistical datasets by using different algorithms [54]. ANN has been widely used in pattern recognition and classification studies [55]. Therefore, classifications of the landscape in different ordinal areas of the GES zone are treated as a classification problem. Different types of algorithms have been used in ANN modeling; among them, multi-layer perceptron (MLP) is the most popular, based on its outcome results and frequency of use by researchers [56]. To run and analyze ANN algorithms, some basic knowledge is needed to understand the structure of input data and the relationship between the variables [57]. The ANN model with the MLP algorithm consists of three layers, namely, the input layer, hidden layer, and output layer. A schematic diagram of the feed-forward artificial neural network model is shown in Figure 5. In this research work, the input layers are training points for the erosion of the gully and the various GECFs, which have finally been connected to the output layer. Input nodes help to predict and analyze the model structure through input and hidden layers and, ultimately, to evaluate the output layer result $[58,59]$. This output layer gives us the GES map. The output layer consists of Boolean values of 0 and 1 , in which 0 represents non-gully erosion and 1 represents gully erosion. Feed-forward of the ANN algorithm model deals with three stages, namely, feed-forward of input data, calculation, and backpropagation of related errors and their adjustments [57].

The novelty of the ANN model is that it can learn the model through a non-linear and complex relationship. Thus, the model's uniqueness is evaluated based on observation of the coherence of the network dynamics compared with the other models. It also has the ability of model generalization and can predict unseen data within the model through understanding the hidden relationship.

The ANN algorithms were elaborated using the following equations by Hagan et al. (1996):

$$
n e t_{j}^{l}(t)=\sum_{i=o}^{p}\left(y_{i}^{i-1}(t) w_{j i}^{l}(t)\right)
$$


The net input of the $j$ th neuron of layer $l$ and iiteration

$$
\begin{gathered}
y_{j}^{l}(t)=f\left(n e t_{j}^{(l)}(t)\right. \\
f(n e t)=\frac{1}{1+e^{(-n e t)}} \\
e_{j}(t)=c_{j}(t)-a_{j}(t) \\
\delta_{j}^{l}(t)=e_{j}^{l}(t) a_{j}(t)\left[1-a_{j} x(t)\right]
\end{gathered}
$$

$\delta$ factor for the $j$ th neuron in the $i$ th output layer

$$
\delta_{j}^{l}(t)=y_{j}^{l}(t)\left[1-y_{j}(t)\right] \sum \delta_{j}^{l}(t) w_{k j}^{(l+1)}(t)
$$

$\delta$ factor for the $j$ th neuron in the $i$ th hidden layer

$$
w_{j i}^{l}(t+1)=w_{j i}^{l}(t)+\alpha\left[w_{j i}^{l}(t)-w_{j i}^{l}(t-1)\right]+n \delta_{j}^{(l)}(t) y_{j}^{(l-1)}(t)
$$

where $\alpha$ is the momentum rate and $n$ is the learning rate.

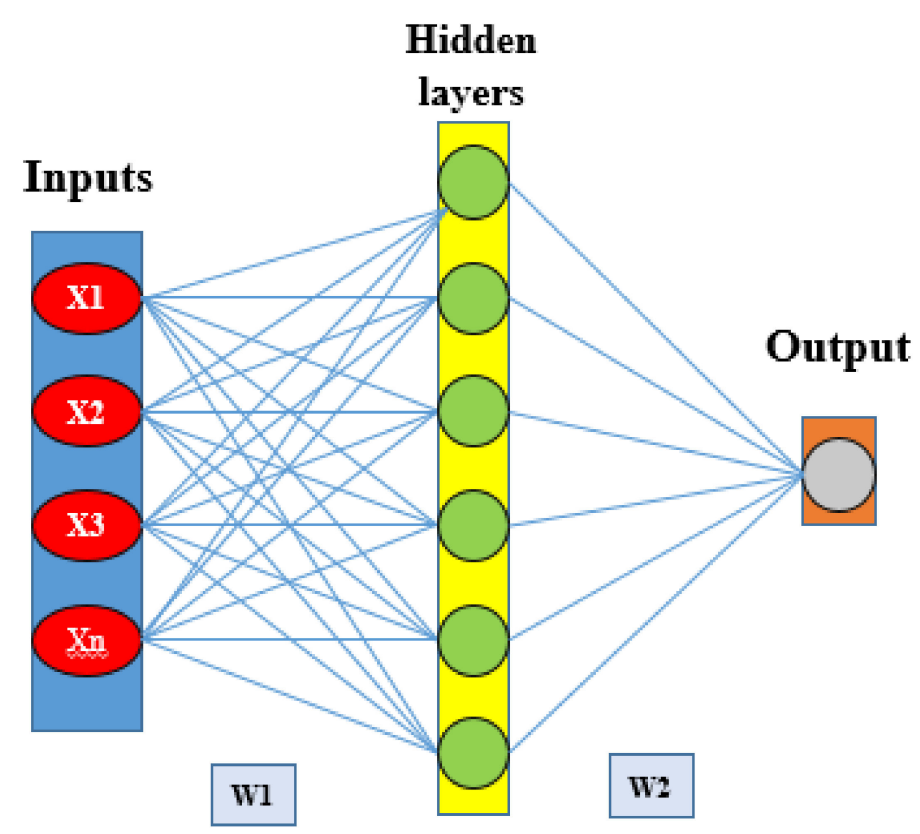

Figure 5. Schematic of feed-forward artificial neural network.

\subsubsection{Deep Learning Neural Network (DLNN)}

DLNN is a well-accepted machine learning model among research groups throughout the world. This ML model has a prominent advantage in appropriately constructing a high-level feature by using the raw dataset [27]. DLNN consists of three layers, i.e., an input layer, several hidden layers, and resulting in an output layer [60]. The speculative configuration of the DLNN model used for GES mapping in this research work is shown in Figure 6. The general structure of the DLNN model is to run in such a way that the input layer receives signals that are different GECFs, this information is processed and analyzed in several hidden layers, and finally, the output model's result is presented in the last layer, i.e., the output layer. The output layer has two possible labels, i.e., the first one is a negative label (non-gully erosion) and the second one is a positive label (gully erosion). These classification results are obtained from the last hidden layer and shown in the output layer [61]. 


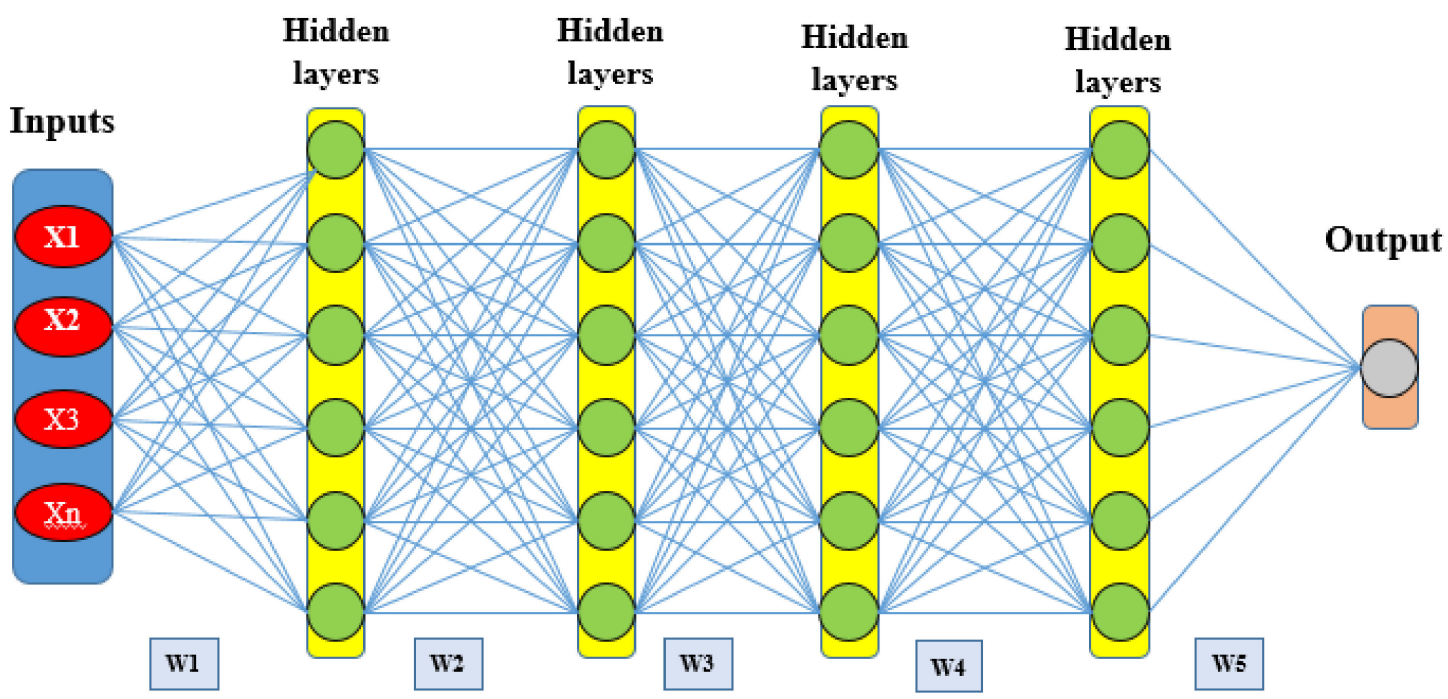

Figure 6. Schematic of deep learning neural network.

DLNN has some specific compensations over the traditional ML algorithm, and thus, in the field of prediction analysis, the use of the DLNN model has been given much more emphasis. Therefore, DLNN has showed some novel performances over the other ML models, namely, maximum utilization of unstructured data through relevant insights to understand the training dataset, being robust enough to recognize the novel data, and being able to develop additional learning models through adding more layers into the neural network system.

According to Kim (2017), the following mathematical equation is used in a DLNN machine learning model:

$$
h(x)=\left\{\begin{array}{l}
x \text { if } x>0 \\
0 \text { if } x \leq 0
\end{array}=\max (0, x)\right.
$$

where $x$ represents the input signal, and $h$ indicates the activation function.

Based on the ReLU activation function, this can be as expressed as follows:

$$
h^{\prime}(x)=\left\{\begin{array}{l}
1 \text { if } x>0 \\
0 \text { if } x \leq 0
\end{array}\right.
$$

The cost function is the difference between experiential and predicted class outputs. The loss function $(L)$ of a cross-entropy used for pattern recognition and expressed as follows:

$$
L=-\frac{1}{N_{D}} \sum_{n=1}^{N_{D}} T 1 n(Y)+(1-T) 1 n(1-Y)
$$

where $N_{D}$ represents the number of the training datasets, $T$ indicates observed class outputs, and $Y$ indicates predicted class outputs.

\subsubsection{Particle Swarm Optimization (PSO)}

The algorithm of PSO is a meta-heuristic and was originally developed by an American social psychologist named Kennedy [62]. In our research work, we are faced with some non-linear problems, and to find the correct solution, the PSO method was developed and widely used. The PSO algorithm was used to locate the best possible food route for bird and fish intelligence. Here, birds are the particles and try to find a solution to the problem. Particles always try to find the best possible solution to a problem through $n$-dimensional space, in which $n$ represents each problem's different parameters [63]. Optimization of position and velocity is the basic principle of each particle. 
Therefore, let us suppose that $x_{i}^{t}=\left(x_{i 1}^{t}, x_{i 2}^{t}, \ldots, x_{i n}^{t}\right)$ and $v_{i}^{t}=\left(v_{i 1}^{t}, v_{i 2}^{t}, \ldots, v_{i n}^{t}\right)$ are the position and velocity of changing position designed for the $i$ th particle in the $t$ th iteration accordingly. The following equations are used for the $i$ th particle's position and velocity in the $(t+1)$ th iteration:

$$
\begin{gathered}
v_{i}^{t+1}=\omega \cdot v_{i}^{t}+c_{1} \cdot r_{1} \cdot\left(p_{i}^{t}-x_{i}^{t}\right)+c_{2} \cdot r_{2} \cdot\left(g_{i}^{t}-x_{i}^{t}\right) w i t h-v_{\max } \leq v_{i}^{t+1} \leq v_{\max } \\
x_{i}^{t+1}=\left(x_{i}^{t}+v_{i}^{t+1}\right)
\end{gathered}
$$

where $x_{i}^{t}$ represents the previous $i$ th position; $p_{i}^{t}$ represents the optimal found position; $g_{i}^{t}$ represents the particle's best position; $r_{1}$ and $r_{2}$ represent random numbers of either 0 or 1 ; $\omega$ is weights of inertia; $c_{1}$ is a coefficient; and $c_{2}$ represents the social coefficient. There are numerous methods for particle weight assignment $[64,65]$; among them, standard 2011 PSO has been widely used and can be calculated by the following equation:

$$
\omega=\frac{1}{2 \operatorname{In} 2} \text { and } c_{1}=c_{2}=0.5+\operatorname{In} 2
$$

Therefore, it is believed that when the concentration of all particle swarms in a certain point and space has been achieved, the problem has been solved. The intelligence-based PSO algorithm has been widely used in high-efficiency swarm paralleling and optimization property. Using a multi-objective fitness function, PSO determines the quality of several features in a dataset. Finally, the ensemble structure of particle swarm optimization (PSO) and deep learning neural network (DLNN) is shown in Figure 7. Therefore, this ensemble method is the novel approach in this research study for GES mapping with high accuracy.

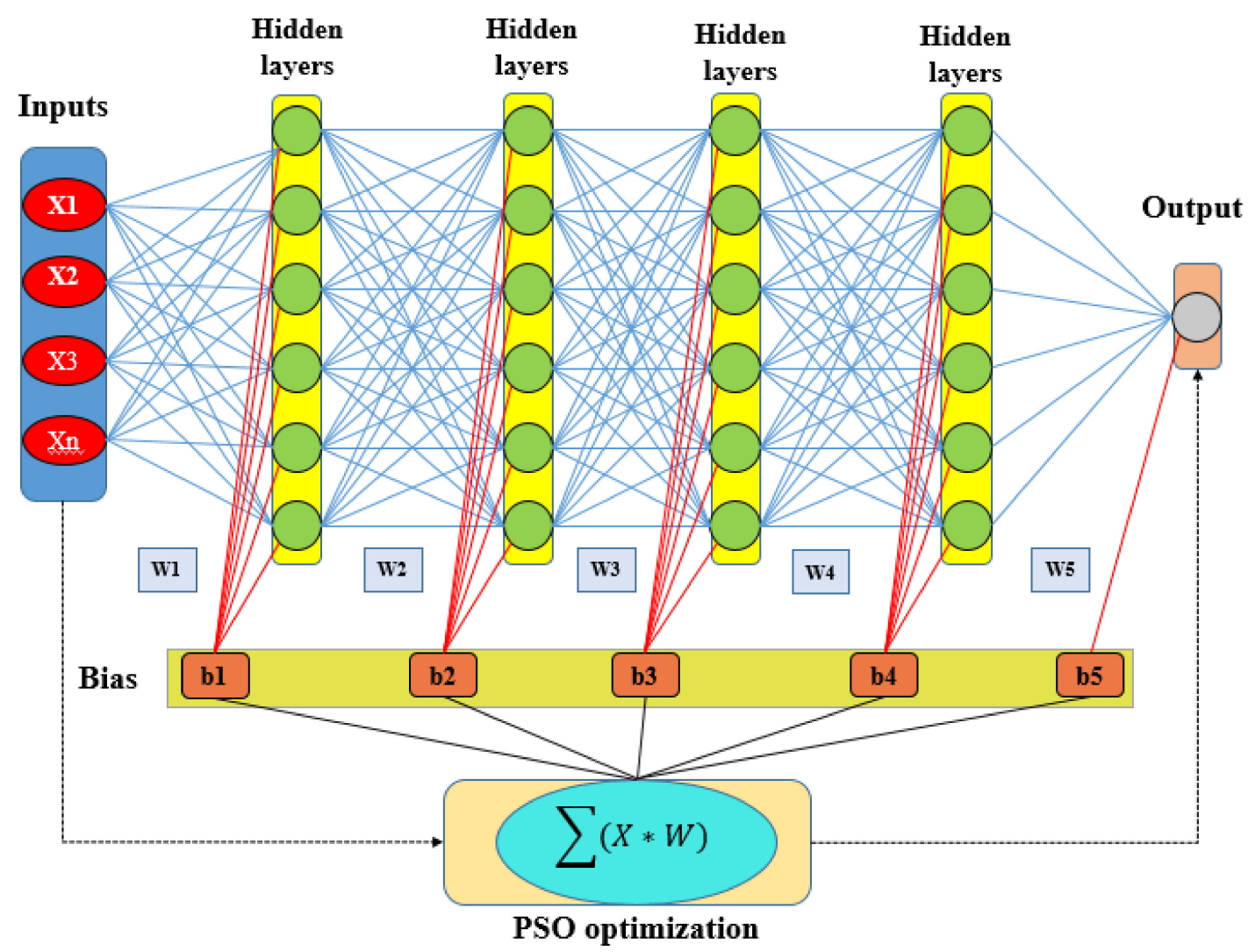

Figure 7. Schematic of ensemble particle swarm optimization and deep learning neural network.

\subsection{Methods of Validation and Accuracy Assessment}

GES maps were prepared based on the prediction performance of the training and validation datasets by using different machine learning models. Therefore, it is necessary to evaluate the model performance to ascertain the validity of the results. In the present research work, statistical indices 
along with the area under the receiver operating characteristic (AUROC) curve were used to predict the accuracy of ML and ensemble models.

\subsubsection{Statistical Indices}

In this study, sensitivity (SST), specificity (SPF), positive predictive values (PPV), and negative predictive values (NPV) were used to evaluate the predictive results. Four types of possible consequences were used to analyze these statistical indices, namely, true positive (TP), true negative (TN), false positive (FP), and false negative (FN). TP is when gully pixels are correctly classified as a gully, and FP is when gully pixels are incorrectly classified as a gully. On the other hand, if gully pixels are correctly or incorrectly classified as non-gully, then they are TN and FN, respectively [36]. If higher values are found among these statistical indices then the model gives better results and vice versa [22]. The following equations were used to calculate the value of these four statistical indices:

$$
\begin{aligned}
& P P V=\frac{T P}{F P+T P} \\
& N P V=\frac{T P}{T P+F N} \\
& S S T=\frac{T P}{T P+F N} \\
& S P F=\frac{T N}{F P+T N}
\end{aligned}
$$

\subsubsection{ROC Curve}

ROC curve is one of the most widely used tools for analyzing the performance validation of the ML model. ROC curve has two dimensions, i.e., events and non-events phenomena [66]. This curve is plotted on ' $X$ ' and ' $Y$ ' co-ordinates, known as sensitivity and 1-specificity, respectively, and represents true positive and false positive. The optimum value in both cases, i.e., in sensitivity (detected gullies) and specificity (detected non-gullies), is 1 [3]. The value of ROC-AUC ranges from 0.5 to 1 , in which 0.5 indicates poor performance and 1 indicates very good performance. Beside this, in a proper way it can be classified into five classes, i.e., poor (0.5-0.6), moderate $(0.6-0.7)$, good $(0.7-0.8)$, very good (0.8-0.9), and excellent (0.9-1) [67]. The following equation was used to compute the ROC-AUC:

$$
S_{A U C}=\sum_{k=1}^{n}\left(X_{k+1}-X_{k}\right)\left(S_{k}+1-S_{k+1}-\frac{S_{k}}{2}\right)
$$

where $S_{A U C}$ indicates area under the curve, $X_{k}$ indicates 1-specificity, and $S_{k}$ indicates the sensitivity of the receiver operating characteristic (ROC) curve.

Besides the above validation methods, here we also used Likelihood Ratio (LR), F-measure, and Maximum Probability of Correct Decision (MPCD) analyses to better understand the accuracy assessment of the result. In this study, the LR model is the relationship between the distribution of gully head-cut points and related GECFs. Therefore, the LR model emphasized the ratio of the probability of events and non-events phenomena of the gully occurrences. In this method, if the ratio is higher than 1 , there is a high relationship among the gully erosion and associated factors. On the other hand, if the ratio is less than 1 , a low relationship is found between the gully erosion and associated factors. Thus, the linear relationship of LR can be expressed as follows:

$$
G E S I=\sum F r
$$

where GESI represents the gully erosion susceptibility index, and $F r$ represents the rating of several factors' range. 
F-measure is a popular validation method in the field of classification and information retrieval communities. F-measure balances between precision and recall. The following equation was used to calculate the F-measure in this study:

$$
F-\text { measure }=2 \times T P / 2 \times T P+F P+F N
$$

In a classification performance, MPCD is a probabilistic-based measure. It is a sensitive method for recognition of class rather than just to estimate the proportion of guesses. The following equation was used to calculate the MPCD:

$$
M P C D=(1-\alpha)(1-\beta)
$$

where $\alpha$ is $\frac{F P}{F P+T N}$ and $\beta$ is $\frac{F N}{F N+T P}$.

\section{Results}

\subsection{Multi-Collinearity Analysis}

Maintaining the given VIF and TOL limits, 13 gully erosion conditioning parameters were selected for gully erosion modeling. The co-linear factors (i.e., distance from a road, geomorphology, and bulk density) were excluded from this analysis. The three factors of distance from a road (TOL 0.028 and VIF 35.65), geomorphology (TOL 0.032 and VIF 31.63), and bulk density (TOL 0.022 and VIF 45.23) are associated with co-linearity problems. The range of VIF for the selected parameters is 1.06 to 3.04 . In the case of TOL, the range of variation among the selected conditioning factors is 0.33 to 0.94 (Table 3). Among the 13 GECFs, altitude has the highest VIF value of 3.04 and the lowest TOL value of 0.33 . On the other hand, the aspect factor has the highest TOL value of 0.94 and the lowest VIF value of 1.06. Therefore, this indicates that no multi-collinearity has been found between the thirteen conditioning factors of gully erosion used in this study.

Table 3. Multi-collinearity analysis to determine the linearity of the independent variables.

\begin{tabular}{ccc}
\hline Variables & VIF & Tolerance \\
\hline Altitude & 3.04 & 0.33 \\
Slope & 1.34 & 0.75 \\
Aspect & 1.06 & 0.94 \\
Plan curvature & 1.83 & 0.55 \\
Profile curvature & 1.82 & 0.55 \\
Distance from river & 2.93 & 0.34 \\
Drainage density & 2.07 & 0.48 \\
Rainfall & 1.41 & 0.71 \\
Land use & 1.81 & 0.55 \\
Lithology & 2.07 & 0.48 \\
Soil & 1.11 & 0.90 \\
SPI & 1.58 & 0.63 \\
TWI & 1.94 & 0.52 \\
\hline
\end{tabular}

\subsection{Gully Erosion Susceptibility Modeling}

In the SVM model, the very low GES areas are mainly concentrated in the eastern and northern portions of the region. The low GES areas are mainly found in the middle and western parts of the region. The moderate susceptibility areas are mainly concentrated in the middle and southern parts of the region (Figure 8a). The very high and high GES areas are mainly found in the southern portion of the watershed. The areal coverages of very low, low, moderate, high, and very high gully erosion susceptibility areas in the SVM model are $65.86(52.08 \%), 28.92(22.87 \%), 10.7(8.46 \%), 8.0(6.33 \%)$, and $12.97 \mathrm{~km}^{2}(10.26 \%)$, respectively (Table 4$)$. 


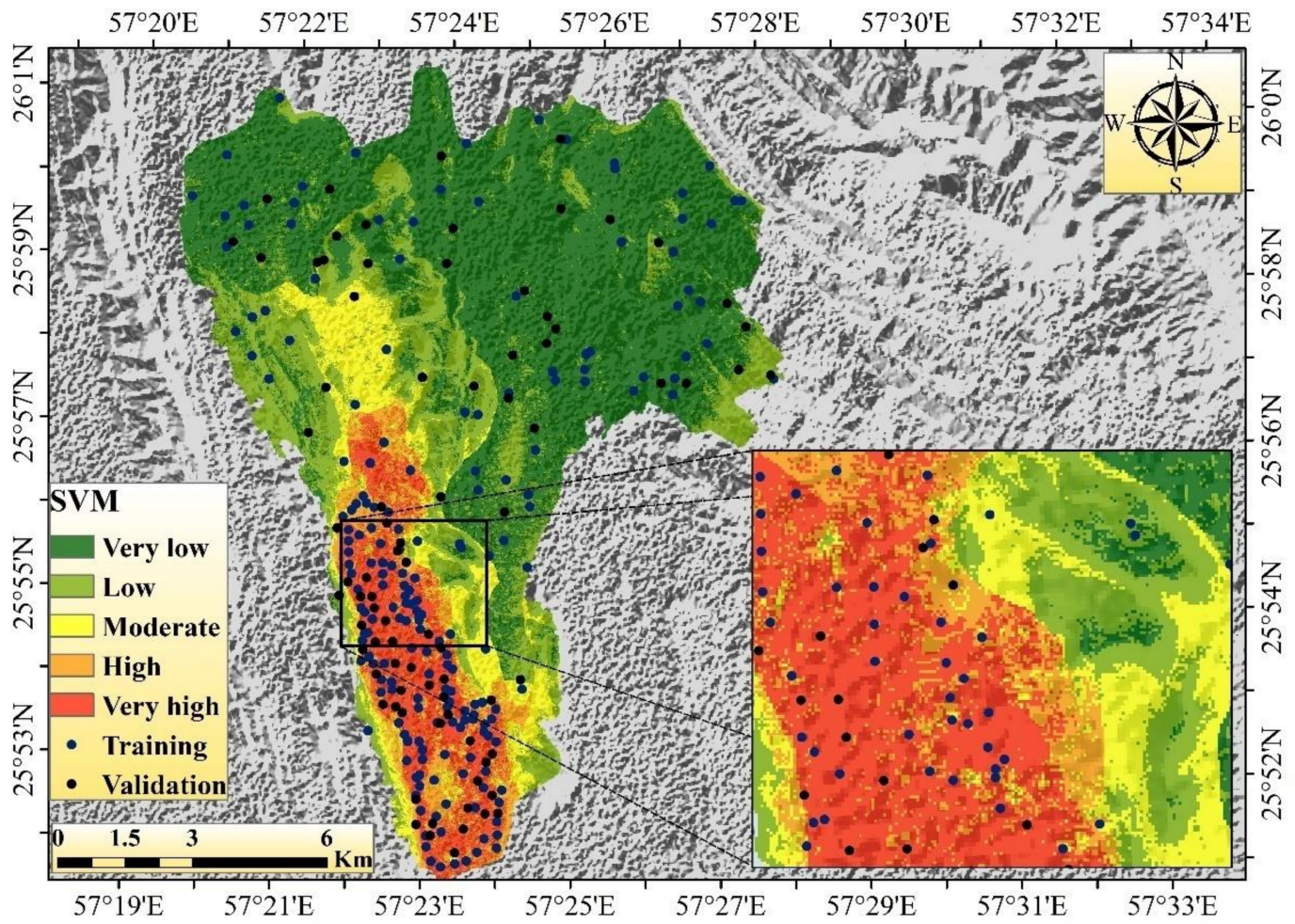

(a)

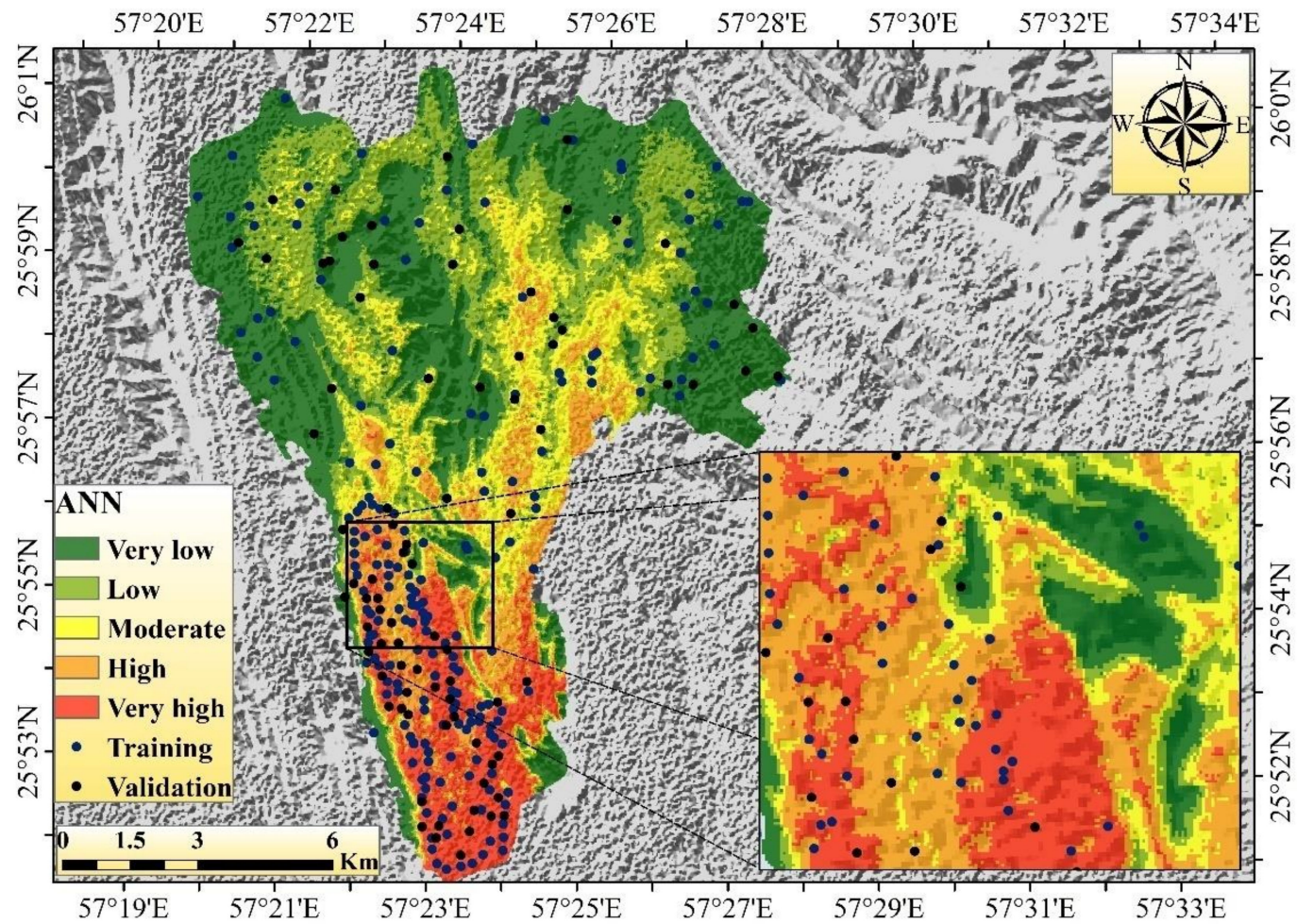

(b)

Figure 8. Cont. 


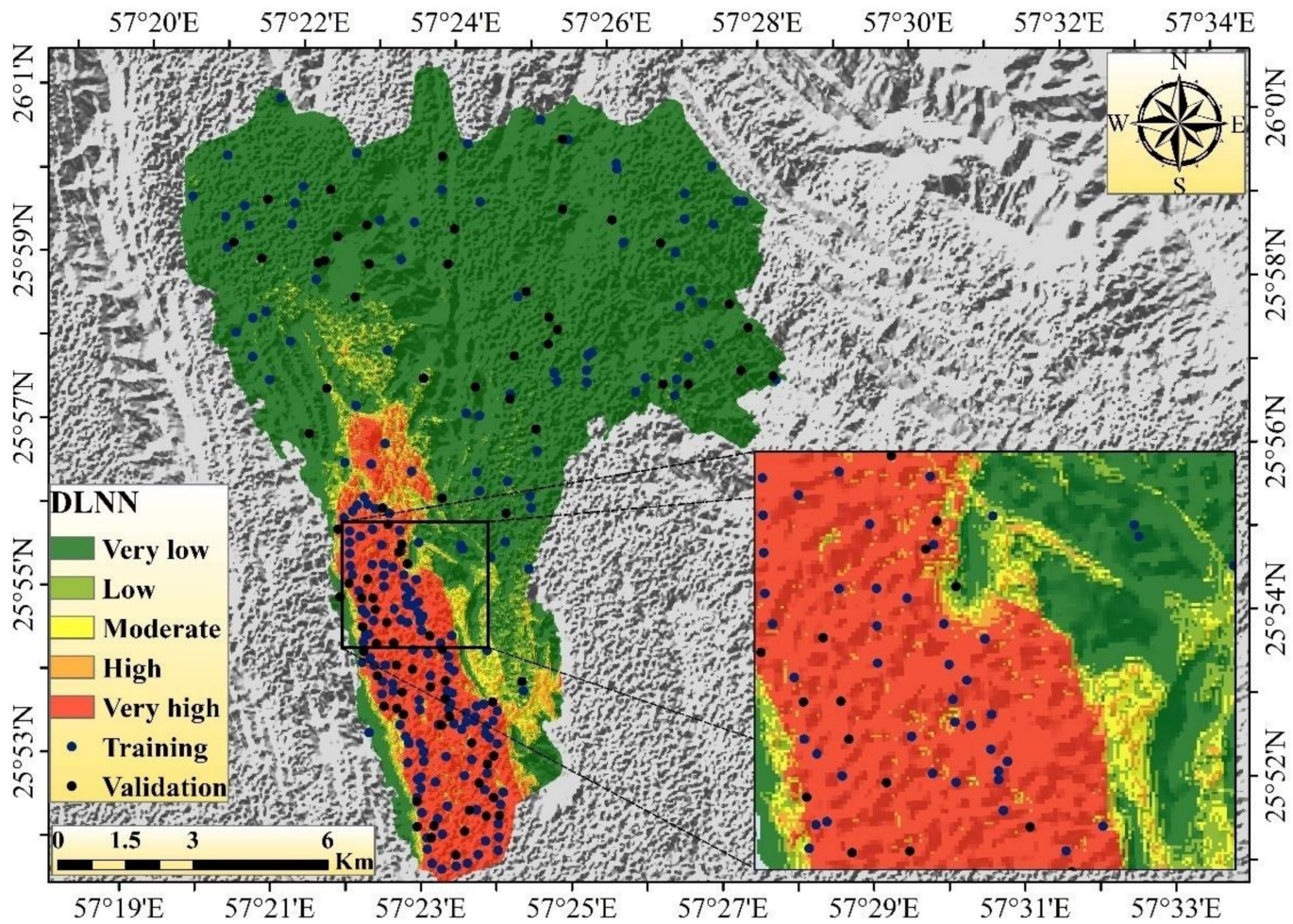

(c)

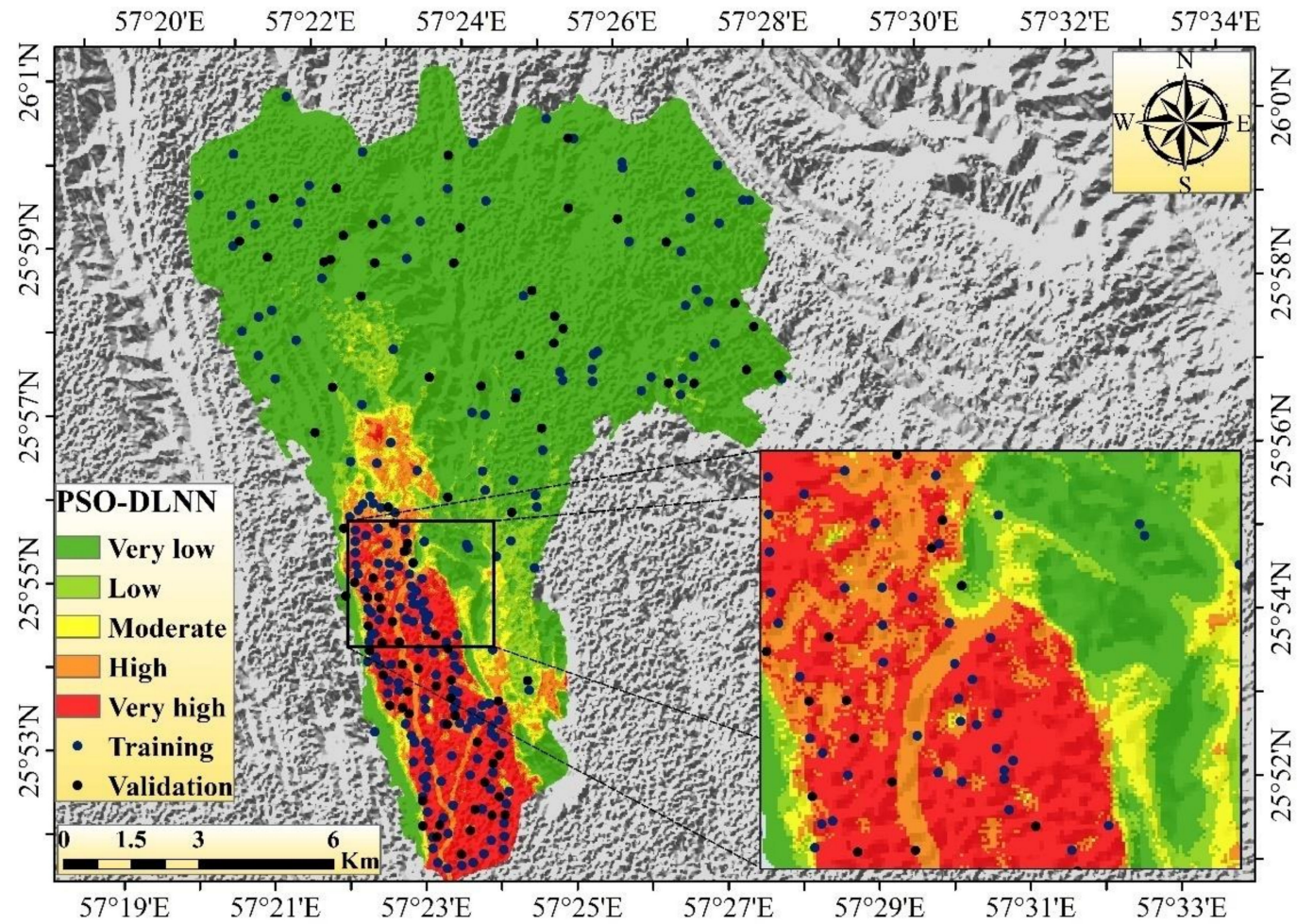

(d)

Figure 8. Head-cut gully erosion map using the four models: (a) SVM; (b) ANN; (c) DLNN; (d) PSO-DLNN. 
Table 4. Areas of gully erosion susceptibility classes.

\begin{tabular}{ccccccc}
\hline \multirow{2}{*}{ Models } & \multirow{2}{*}{ Area } & \multicolumn{5}{c}{ Susceptibility Class } \\
\cline { 3 - 7 } & & Very Low & Low & Moderate & High & Very High \\
\hline \multirow{2}{*}{ SVM } & $\mathrm{km}^{2}$ & 65.86 & 28.92 & 10.7 & 8 & 12.97 \\
& $\%$ & 52.08 & 22.87 & 8.46 & 6.33 & 10.26 \\
ANN & $\mathrm{km}^{2}$ & 55.76 & 26.85 & 16.85 & 13.48 & 13.51 \\
& $\%$ & 44.10 & 21.23 & 13.33 & 10.66 & 10.68 \\
DLNN & $\mathrm{km}^{2}$ & 96.34 & 5.85 & 2.73 & 3.17 & 18.36 \\
& $\%$ & 76.19 & 4.63 & 2.16 & 2.51 & 14.52 \\
PSO-DLNN & $\mathrm{km}^{2}$ & 94.58 & 8.15 & 4.03 & 6.31 & 13.38 \\
& $\%$ & 74.80 & 6.45 & 3.19 & 4.99 & 10.58 \\
\hline
\end{tabular}

In ANN, the areal coverages for very low, low, moderate, high, and very high gully erosion susceptibility areas are $55.76(44.10 \%), 26.85(21.23 \%), 16.85(13.33 \%), 13.48(10.66 \%)$, and $13.51 \mathrm{~km}^{2}$ $(10.68 \%)$, respectively. According to the GES map of the ANN model, the largest portion of the area is occupied by very low $(44.10 \%)$ to low $(21.23 \%)$ susceptibility classes, while very high $(10.68 \%)$, high $(10.66 \%)$, and moderate (13.33\%) susceptibility classes cover the rest of the studied region. In this model, the very high, high, and moderate susceptibility areas are mainly concentrated in the southern, middle, and eastern portions of the watershed (Figure $8 b$ ). The rest of the portion of this watershed is associated with very low to low GES zones.

In the case of DLNN, the areal coverages for very low, low, moderate, high, and very high gully erosion susceptibility zones are $96.34(76.19 \%), 5.85(4.63 \%), 2.73(2.16 \%), 3.17(2.51 \%)$, and $18.36 \mathrm{~km}^{2}$ $(14.52 \%)$, respectively. According to the GES map of the DLNN model, the largest portion of the area is occupied by very low $(76.19 \%)$ to low $(28.73 \%)$ susceptibility classes, while very high $(14.52 \%)$, high $(2.51 \%)$, and moderate $(2.16 \%)$ susceptibility classes occupy the rest of the studied region. In this model, the very high to moderate susceptibility areas are mainly concentrated in the southern and middle portions of the watershed, and the rest of the portions are associated with very low to low susceptibility zones (Figure 8c).

In the PSO-DLNN model, the areal coverages of low, low, moderate, high, and very high gully erosion susceptibility zones are $94.58(74.80 \%), 8.15(6.45 \%), 4.03(3.19 \%), 6.31(4.99 \%)$, and 13.38 $(10.58 \%) \mathrm{km}^{2}$, respectively. According to the GES map of the PSO-DLNN model, the major portion of the area is occupied by very low $(74.80 \%)$ to low $(6.45 \%)$ susceptibility classes, while very high $(10.58 \%)$, high $(4.99 \%)$, and moderate $(3.19 \%)$ susceptibility classes cover the rest of the studied region respectively. Very high, high, and moderate gully erosion susceptibility zones mainly occupy the southern portion of the watershed, and the rest of the portions are associated with very low to low susceptibility zones (Figure $8 \mathrm{~d}$ ).

\subsection{Validation of the Models}

PSO-DLNN is the most optimal model in this analysis and is associated with maximum accuracy. The AUC value from ROC considering the testing datasets of PSO-DLNN is 0.89 , which is associated with superb accuracy. The rest of the models are also associated with optimal accuracy and have similar values to the PSO-DLNN model; the AUC values from ROC of DLNN, SVM, and ANN for testing datasets are $0.87,0.85$, and 0.84 , respectively (Figure 9). Apart from this, various statistical indices were considered for estimating the optimal capacity of all the models for GES modeling. The values of sensitivity in PSO-DLNN, DLNN, SVM, and ANN for training datasets are 0.98, 0.95, 0.99, and 0.99, respectively. The same values for the validation datasets in PSO-DLNN, DLNN, SVM, and ANN are $0.95,0.90,0.82$, and 0.95 , respectively. The values of specificity for the training datasets in PSO-DLNN, DLNN, SVM, and ANN are $0.85,0.82,0.86$, and 0.87 , respectively. In the case of validation datasets, the values of specificity in PSO-DLNN, DLNN, SVM, and ANN are 0.74, 0.74, 0.69, and 0.67, respectively. The values of PPV in the case of training datasets in PSO-DLNN, DLNN, SVM, and ANN 
are $0.87,0.85,0.88$, and 0.89 , respectively. When we consider the validation datasets, the values of PPV in PSO-DLNN, DLNN, SVM, and ANN are 0.77, 0.77, 0.71, and 0.73 (Table 5). In PSO-DLNN, DLNN, SVM, and ANN models, the values of NPV for the training datasets are 0.97, 0.94, 0.99, and 0.99 , respectively. In the case of validation datasets, the values of NPV in PSO-DLNN, DLNN, SVM, and ANN are $0.94,0.89,0.81$, and 0.93 , respectively. The F-measure values in validation datasets for PSO-DLNN, DLNN, SVM, and ANN models are $0.66,0.635,0.63$, and 0.64 , respectively.

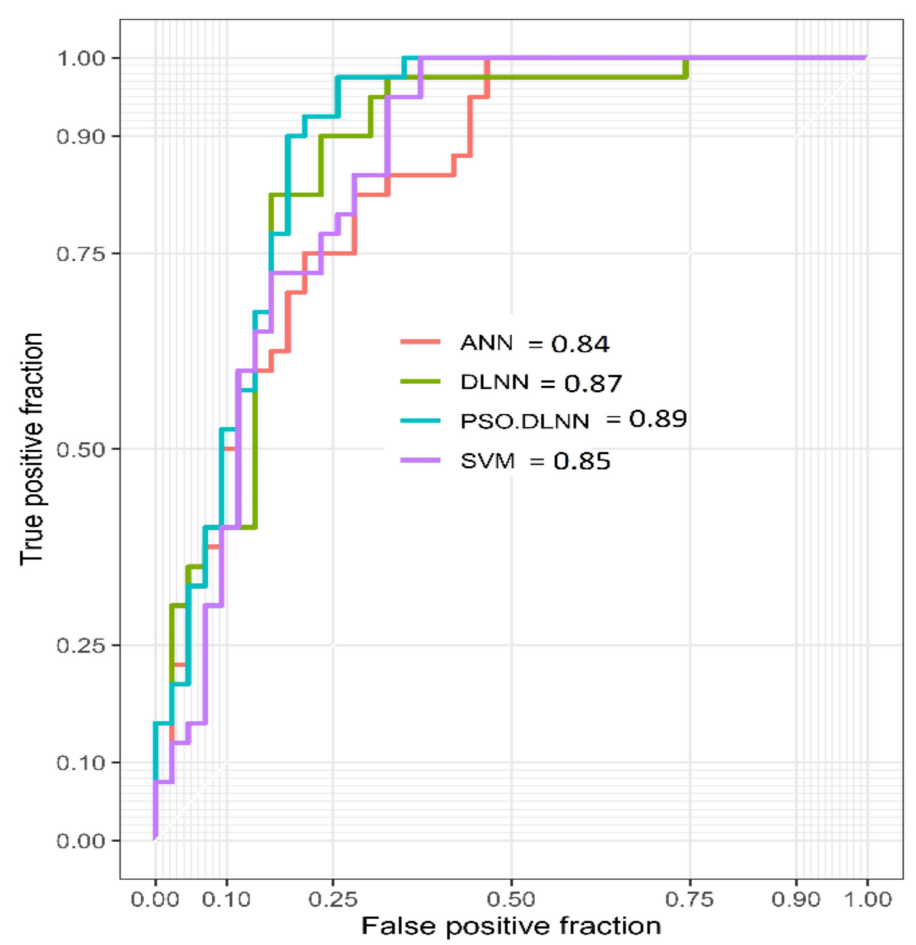

Figure 9. Receiver operating characteristic (ROC) curve analysis for four head-cut gully erosion models using the testing dataset.

Table 5. Predictive capability of guully erosion susceptibility (GES) models using training and testing datasets.

\begin{tabular}{cccccccc}
\hline \multirow{2}{*}{ Models } & \multirow{2}{*}{ Stage } & \multicolumn{7}{c}{ Parameters } \\
\cline { 3 - 8 } & & Sensitivity & Specificity & PPV & NPV & AUC & F-Measure \\
\hline \multirow{2}{*}{ SVM } & Training & 0.99 & 0.87 & 0.89 & 0.99 & 0.94 & 0.84 \\
& Validation & 0.95 & 0.67 & 0.73 & 0.93 & 0.85 & 0.63 \\
\multirow{2}{*}{ ANN } & Training & 0.99 & 0.86 & 0.88 & 0.99 & 0.94 & 0.83 \\
& Validation & 0.82 & 0.69 & 0.71 & 0.81 & 0.84 & 0.64 \\
DLNN & Training & 0.95 & 0.82 & 0.85 & 0.94 & 0.91 & 0.82 \\
& Validation & 0.90 & 0.74 & 0.77 & 0.89 & 0.87 & 0.65 \\
PSO-DLNN & Training & 0.98 & 0.85 & 0.87 & 0.97 & 0.93 & 0.84 \\
& Validation & 0.95 & 0.74 & 0.77 & 0.94 & 0.89 & 0.66 \\
\hline
\end{tabular}

Details about DLNN and its associated parameters are shown in Table 6. Details about the combination of PSO and DLNN and its associated parameters are shown in Table 7 . The values of population, iteration, phi, phi1, phi2, $\mathrm{W}, \mathrm{C} 1, \mathrm{C} 2$, and best cost are 50, 500, 4.1, 2.05, 2.05, 0.73, 1.49, 1.49, and 0.26 . The objective cost function of the PSO-DLNN model is shown in Figure 10. 
Table 6. Results of optimal parameters in the DLNN model.

\begin{tabular}{cc}
\hline Parameters & Optimum \\
\hline Input number of units & 13 \\
Output & 2 \\
Activation Function & ReLU \\
Activation & 'softmax' \\
Function & Sigmoid \\
reluLeak & 0.01 \\
eta & 0.8 \\
Hidden layer unit & $3-3$ \\
Iteration & 200 \\
\hline
\end{tabular}

Table 7. Parameters used in PSO algorithms in combined DLNN.

\begin{tabular}{cc}
\hline Parameters & Number \\
\hline Population & 50 \\
Iteration & 500 \\
phi & 4.1 \\
phi1 & 2.05 \\
Phi2 & 2.05 \\
W & 0.73 \\
C1 & 1.49 \\
C2 & 1.49 \\
Best Cost & 0.26 \\
\hline
\end{tabular}

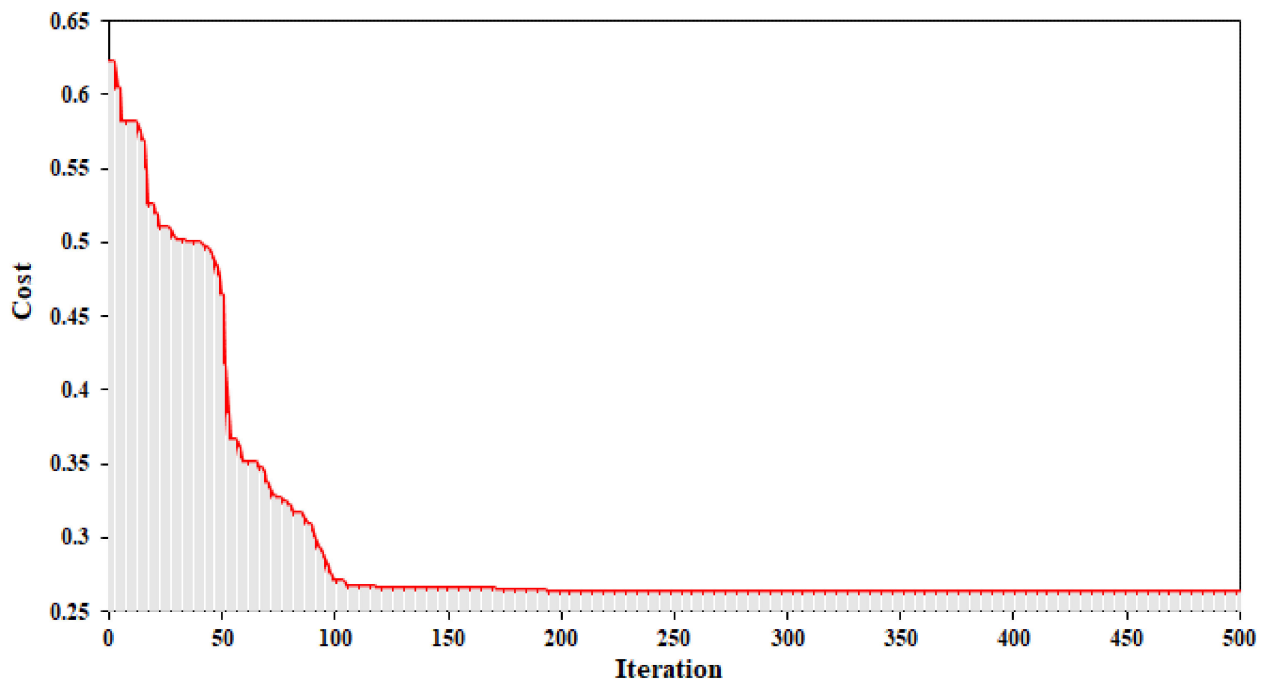

Figure 10. Convergence graph of the objective cost function (MSE) in the PSO-DLNN model.

\subsection{Variable Importance}

The conditioning factor for GES modeling for this region was selected considering the different kinds found in the literature. The most important parameters for the creation and development of gullies in this region are land use, altitude, lithology, rainfall, and distance from a road, etc. The relative importance of land use, altitude, lithology, rainfall, and distance from a road for the GES models are $100,97.94,59.51,46.94$, and 29.48, respectively. The rest of the factors (i.e., profile curvature, TWI, plan curvature, slope, soil, drainage density, SPI, and aspect) are associated with moderate to very low relative importance for GES. The relative importance of profile curvature, TWI, plan curvature, slope, soil, drainage density, SPI, and aspect for gullies are 16.22, 14.37, 11.31, 7.89, 7.1, 6.91, 5.12, and 0 (Table 8). Here, apart from the topographical and geohydrological characteristics, the impact of anthropogenic activities accelerates the rate of land degradation in the form of gullies. 
Table 8. Variable importance analysis based on the PSO-DLNN model.

\begin{tabular}{cc}
\hline Variables & Importance \\
\hline Altitude & 97.94 \\
Aspect & 0 \\
Slope & 7.89 \\
Plane curvature & 11.31 \\
Profile curvature & 16.22 \\
Drainage density & 6.91 \\
Distance from river & 29.48 \\
Land use & 100 \\
Lithology & 59.51 \\
Soil & 7.1 \\
Rainfall & 46.94 \\
SPI & 5.12 \\
TWI & 14.37 \\
\hline
\end{tabular}

\section{Discussion}

Land degradation through various forms of soil erosion can cause extensive damage, and it has an adverse impact on society and people's livelihoods throughout the world [68]. There are various forms of erosion, i.e., sheet erosion, formation of rills, formation and development of gullies and ravines, etc. [69]. Of these, the formation and development of gullies and their associated erosion is the most destructive element of land degradation worldwide [2]. Although it is a natural process of erosion, this process can be greatly accelerated by anthropogenic activities and have a serious impact on the ecosystem [70]. With this type of erosion, agricultural activities have not only affected it but have also been associated with damage to manmade infrastructure. On the one hand, this erosion is responsible for removing the top soil, but on the other hand, it is responsible for the creation and accumulation of sediment in the lower catchment area [71]. The life span of the reservoir will cause serious damage to the sediment deposition resulting from this type of erosion [72,73].

Shirahan watershed in Iran has recently faced severe gully erosion, which is responsible for large-scale erosion and is the main barrier to sustainable land management practices. Therefore, identifying vulnerable regions with the most optimal model is very useful so that appropriate soil and water conservation measures can be put in place. For this purpose, we considered SVM, ANN, DLNN, and PSO-DLNN in order to estimate the GES of this region with the maximum possible accuracy and to suggest the most suitable model. The erosion of a gully is controlled by various causal factors, and we attempted to determine the importance of these factors for gulling. Apart from the topographic and hydrogeomorphic attributes, land use is the most important variable for gully erosion, which indicates the large anthropogenic impact on the development of gullies. Other factors, such as altitude, lithology, rainfall, and the distance from a river, are very influential too on gully erosion and promote gulling. The transformation of land use is a crucial element and is responsible for large-scale erosion [74]. Alterations in land use influence landscape ecology functions, with far-reaching implications for natural ecosystems and land reclamation [75]. The character and volume of the surface runoff may change directly with the changing pattern of land use in the region. From this perspective, the nature of erosion in the form of gullies can have a significant effect on the impact of rainfall and its associated runoff characteristics in a changing environment. This type of outcome is similar to some of the findings from the studies of a number of researchers in this diversified discipline. This finding has been highlighted by many other contributions in which morphological and geological properties are assigned as the determinants of the highest possible location of GES [24,76]. Other research outcomes suggest that environmental and hydrological parameters are very significant and responsible for gulling.

All the predicted models are associated with high accuracy, but PSO-DLNN is the most optimal, with the AUC of this model being 0.89 . The efficiency of all predicted models is excellent, with the AUC values for DLNN, SVM, and ANN being 0.87, 0.85, and 0.84, respectively. Apart from this, 
considering various statistical indices, PSO-DLNN is the best model among the models used in this study. According to the PSO-DLNN model, $18.76 \%$ of the total area is associated with a moderate to very high susceptible area of gully erosion. The southern portion of this watershed is mainly associated with higher gully occurrences. The complex geohydrological characteristics of this region are favorable for large-scale erosion in the form of gullies.

A deep learning framework is associated with higher accuracy compared with conventional ANN and SVM ML methods. This model can handle a larger number of samples and even a large amount of big data, and can estimate the results with optimum accuracy. The traditional ML algorithm is not capable of handling this large a number of samples, and the outcome from this perspective is less optimal compared to the deep learning framework. Significant progress in DLNN-dependent deep learning (DL) systems has significantly increased the consistency of machine learning for various purposes. While the standardized features of multi-layer NNs are well-established, the main advantage of DL is its structured method of self-governing the training of DLNN layer organizations. The benefits of structured data and expertise descriptions were recognized before the recent increase in interest in DLNNs. This definition is widespread in the physical sciences where the proposed method is popular for both specific theoretical structures and complicated system implementations in practice.

First, PSO produces an arbitrary solution and then discovers accurate solutions with an incremental optimum fitness attribute. This type of methodology has already been used primarily for backpropagation (BP) genetic algorithms, due to the efficiency of simple installation, fast response, and accuracy of predictions. It also demonstrated dominance in the resolution of complex applications and was initially implemented in the context of DL. The best function of the PSO algorithm is to combine various particles that are interlinked to each other to achieve an optimum position. The same technique indicates the position, velocity, and highest accuracy of each particle, which are dictated by the basic concepts used to enhance the problem. Particularly in comparison to other optimization algorithms, the advantage of the PSO algorithm is that the PSO technique usually involves a quick and important search procedure, is easy to perform, and can find the globally optimal path that is closest to the concrete ideas.

\section{Conclusions}

It is necessary to choose the most efficient machine learning algorithm in order to decrease the inconsistencies associated with predicting gully erosion susceptibility. The main objectives in most cases of susceptibility modeling are to identify the optimal model according to its predictive capabilities. The identification of key parameters for the formation and development of gullies is necessary to estimate the susceptibility mapping of the spatial distribution of gully erosion. Therefore, to control damage in the future, it is important to make an appropriate selection of a model to manage areas that are prone to gully degradation. The primary objective of this research was to estimate the optimal model with maximum predictive capability. For this reason, various ML algorithms, i.e., ANN, SVM, DLNN, and PSO, were considered for estimating the GES zone with optimal capacity. PSO-DLNN is the best-fitted model and is associated with the highest AUC value (0.89). Here, all the datasets were randomly partitioned with a 70/30 ratio as training and validation datasets. Topographical, hydrological, and environmental factors were most dominant and were influential factors in susceptibility modeling. The role of land use in susceptibility modeling is more significant than that of any other component. Most of the region of this watershed is associated with very low to low susceptibility zones, while $15.57 \%$ of the area is associated with a very high susceptibility zone. This study region must take appropriate planning initiatives to reduce the level of vulnerability and to protect this precious resource. In future research, it would be desirable to develop the PSO-DLNN algorithm by incorporating some new components or to develop the same algorithm with slight modifications. This would be a great contribution to the research community as well as to society. Apart from this, the selection of inappropriate parameters can reduce the efficiency of the predicted models. Thus, the selection of the most appropriate variables for susceptibility modeling is one of the important tasks for researchers. 
Author Contributions: S.J. acquired the data; S.J., S.S.B., S.C.P. and A.M. conceptualized and performed the analysis; S.S.B., S.C.P., A.S., R.C. and M.S. wrote the manuscript, discussion, and analyzed the data; S.S.B. supervised and carried out funding acquisition; S.S.B. and A.M. provided technical insights, as well as edited, restructured, and professionally optimized the manuscript. All authors discussed the results and edited the manuscript. All authors have read and agreed to the published version of the manuscript.

Funding: This research was funded by the Hungarian-Mexican bilateral Scientific and Technological project, grant number 2019-2.1.11-TET-2019-00007.

Acknowledgments: We acknowledge the support of the German Research Foundation (DFG) and the Bauhaus-Universität Weimar within the Open-Access Publishing Program.

Conflicts of Interest: The authors declare no conflict of interest.

\section{References}

1. Keesstra, S.; Mol, G.; De Leeuw, J.; Okx, J.; De Cleen, M.; Visser, S.; Molenaar, C. Soil-related sustainable development goals: Four concepts to make land degradation neutrality and restoration work. Land 2018, 7 , 133. [CrossRef]

2. Lal, R. Soil degradation by erosion. L. Degrad. Dev. 2001, 12, 519-539. [CrossRef]

3. Conoscenti, C.; Angileri, S.; Cappadonia, C.; Rotigliano, E.; Agnesi, V.; Märker, M. Gully erosion susceptibility assessment by means of GIS-based logistic regression: A case of Sicily (Italy). Geomorphology 2014, 204, 399-411. [CrossRef]

4. Vanwalleghem, T.; Poesen, J.; Van Den Eeckhaut, M.; Nachtergaelel, J.; Deckers, J. Reconstructing rainfall and land-use conditions leading to the development of old gullies. Holocene 2005, 15, 378-386. [CrossRef]

5. Zabihi, M.; Pourghasemi, H.R.; Motevalli, A.; Zakeri, M.A. Gully erosion modeling using GIS-based data mining techniques in northern Iran: A comparison between boosted regression tree and multivariate adaptive regression spline. In Natural Hazards GIS-Based Spatial Modeling Using Data Mining Techniques; Springer: Cham, Switzerland, 2019; pp. 1-26.

6. Pimentel, D.; Burgess, M. Soil erosion threatens food production. Agriculture 2013, 3, 443-463. [CrossRef]

7. Arabameri, A.; Rezaei, K.; Pourghasemi, H.R.; Lee, S.; Yamani, M. GIS-based gully erosion susceptibility mapping: A comparison among three data-driven models and AHP knowledge-based technique. Environ. Earth Sci. 2018, 77, 1-22. [CrossRef]

8. Arabameri, A.; Pradhan, B.; Rezaei, K. Gully erosion zonation mapping using integrated geographically weighted regression with certainty factor and random forest models in GIS. J. Environ. Manag. 2019, 232, 928-942. [CrossRef]

9. Vaezi, A.R.; Abbasi, M.; Bussi, G.; Keesstra, S. Modeling sediment yield in semi-arid pasture micro-catchments, NW Iran. L. Degrad. Dev. 2017, 28, 1274-1286. [CrossRef]

10. Poesen, J.; Nachtergaele, J.; Verstraeten, G.; Valentin, C. Gully erosion and environmental change: Importance and research needs. Catena 2003, 50, 91-133. [CrossRef]

11. Poesen, J. Soil erosion in the Anthropocene: Research needs. Earth Surf. Process. Landf. 2018, 43, 64-84. [CrossRef]

12. Valentin, C.; Poesen, J.; Li, Y. Gully erosion: Impacts, factors and control. Catena 2005, 63, 132-153. [CrossRef]

13. Chaplot, V. Impact of terrain attributes, parent material and soil types on gully erosion. Geomorphology 2013, 186, 1-11.

14. Angileri, S.E.; Conoscenti, C.; Hochschild, V.; Märker, M.; Rotigliano, E.; Agnesi, V. Water erosion susceptibility mapping by applying stochastic gradient treeboost to the Imera Meridionale river basin (Sicily, Italy). Geomorphology 2016, 262, 61-76. [CrossRef]

15. Saha, S.; Roy, J.; Arabameri, A.; Blaschke, T.; Tien Bui, D. Machine learning-based gully erosion susceptibility mapping: A case study of Eastern India. Sensors 2020, 20, 1313. [CrossRef] [PubMed]

16. Moradi, H.R.; Avand, M.T.; Janizadeh, S. landslide susceptibility survey using modeling methods. In Spatial Modeling in Gis and $R$ for Earth and Environmental Sciences; Elsevier: Amsterdam, The Netherlands, 2019; pp. 259-276.

17. Watson, G.L.; Telesca, D.; Reid, C.E.; Pfister, G.G.; Jerrett, M. Machine learning models accurately predict ozone exposure during wildfire events. Environ. Pollut. 2019, 254, 112792. [CrossRef] 
18. Arabameri, A.; Pradhan, B.; Rezaei, K.; Yamani, M.; Pourghasemi, H.R.; Lombardo, L. Spatial modelling of gully erosion using evidential belief function, logistic regression, and a new ensemble of evidential belief function-Logistic regression algorithm. L. Degrad. Dev. 2018, 29, 4035-4049. [CrossRef]

19. Dube, F.; Nhapi, I.; Murwira, A.; Gumindoga, W.; Goldin, J.; Mashauri, D.A. Potential of weight of evidence modelling for gully erosion hazard assessment in Mbire District-Zimbabwe. J. Phys. Chem. Earth 2014. [CrossRef]

20. Pourghasemi, H.R.; Youse, S.; Kornejady, A.; Cerdà, A. Performance assessment of individual and ensemble data-mining techniques for gully erosion modeling. Sci. Total Environ. 2017, 609, 764-775. [CrossRef]

21. Roy, P.; Chakrabortty, R.; Chowdhuri, I.; Malik, S.; Das, B.; Pal, S.C. Development of Different Machine Learning Ensemble Classifier for Gully Erosion Susceptibility in Gandheswari Watershed of West Bengal, India. In Machine Learning for Intelligent Decision Science; Springer: Singapore, 2020; pp. 1-26.

22. Gayen, A.; Pourghasemi, H.R. Spatial Modeling of Gully Erosion: A New Ensemble of CART and GLM Data-Mining Algorithms. In Spatial Modeling in GIS and R for Earth and Environmental Sciences; Elsevier: Amsterdam, The Netherlands, 2019; pp. 653-669.

23. Yunkai, L.; Yingjie, T.; Zhiyun, O.; Lingyan, W.; Tingwu, X.; Peiling, Y.; Huanxun, Z. Analysis of soil erosion characteristics in small watersheds with particle swarm optimization, support vector machine, and artificial neuronal networks. Environ. Earth Sci. 2010, 60, 1559-1568. [CrossRef]

24. Saha, A.; Ghosh, M.; Pal, S.C. Understanding the Morphology and Development of a Rill-Gully: An Empirical Study of Khoai Badland, West Bengal, India. In Gully Erosion Studies from India and Surrounding Regions; Springer: Cham, Swizerland, 2020; pp. 147-161.

25. Avand, M.; Janizadeh, S.; Naghibi, S.A.; Pourghasemi, H.R.; Khosrobeigi Bozchaloei, S.; Blaschke, T. A Comparative Assessment of Random Forest and k-Nearest Neighbor Classifiers for Gully Erosion Susceptibility Mapping. Water 2019, 11, 2076. [CrossRef]

26. Shi, S.; Xu, G. Novel performance prediction model of a biofilm system treating domestic wastewater based on stacked denoising auto-encoders deep learning network. Chem. Eng. J. 2018, 347, 280-290. [CrossRef]

27. Ghorbanzadeh, O.; Blaschke, T.; Gholamnia, K.; Meena, S.R.; Tiede, D.; Aryal, J. Evaluation of different machine learning methods and deep-learning convolutional neural networks for landslide detection. Remote Sens. 2019, 11, 196. [CrossRef]

28. Schmidhuber, J. Deep learning in neural networks: An overview. Neural Netw. 2015, 61, 85-117. [CrossRef]

29. Coelho, I.M.; Coelho, V.N.; Luz, E.J.; da S. Luz, E.J.; Ochi, L.S.; Guimarães, F.G.; Rios, E. A GPU deep learning metaheuristic based model for time series forecasting. Appl. Energy 2017, 201, 412-418. [CrossRef]

30. Hong, H.; Pradhan, B.; Sameen, M.I.; Kalantar, B.; Zhu, A.; Chen, W. Improving the accuracy of landslide susceptibility model using a novel region-partitioning approach. Landslides 2018, 15, 753-772. [CrossRef]

31. Berlin, S.J.; John, M. Particle swarm optimization with deep learning for human action recognition. Multimed. Tools Appl. 2020, 79, 1-23. [CrossRef]

32. Poli, R.; Kennedy, J.; Blackwell, T. Particle swarm optimization. Swarm Intell. 2007, 1, 33-57. [CrossRef]

33. Conforti, M.; Aucelli, P.P.C.; Robustelli, G.; Scarciglia, F. Geomorphology and GIS analysis for mapping gully erosion susceptibility in the Turbolo stream catchment (Northern Calabria, Italy). Nat. Hazards 2011, 56, 881-898. [CrossRef]

34. El Maaoui, M.A.; Felfoul, M.S.; Boussema, M.R.; Snane, M.H. Sediment yield from irregularly shaped gullies located on the Fortuna lithologic formation in semi-arid area of Tunisia. Catena 2012, 93, 97-104. [CrossRef]

35. Arabameri, A.; Pradhan, B.; Rezaei, K.; Conoscenti, C. Gully erosion susceptibility mapping using GIS-based multi-criteria decision analysis techniques. Catena 2019, 180, 282-297. [CrossRef]

36. Kalantar, B.; Ueda, N.; Saeidi, V.; Ahmadi, K.; Halin, A.A.; Shabani, F. Landslide Susceptibility Mapping: Machine and Ensemble Learning Based on Remote Sensing Big Data. Remote Sens. 2020, 12, 1737. [CrossRef]

37. Wang, G.; Chen, X.; Chen, W. Spatial Prediction of Landslide Susceptibility Based on GIS and Discriminant Functions. ISPRS Int. J. Geo-Inf. 2020, 9, 144. [CrossRef]

38. Chowdhuri, I.; Pal, S.C.; Chakrabortty, R. Flood susceptibility mapping by ensemble evidential belief function and binomial logistic regression model on river basin of eastern India. Adv. Sp. Res. 2020, 65, 1466-1489. [CrossRef]

39. Youssef, A.M.; Pourghasemi, H.R. Landslide susceptibility mapping using machine learning algorithms and comparison of their performance at Abha Basin, Asir Region, Saudi Arabia. Geosci. Front. 2020. [CrossRef] 
40. Green, I.R.A.; Stephenson, D. Criteria for comparison of single event models. Hydrol. Sci. J. 1986, 31, $395-411$. [CrossRef]

41. Kutner, M.H.; Nachtsheim, C.J.; Neter, J.; Li, W. Applied Linear Statistical Models; McGraw-Hill Irwin: New York, NY, USA, 2005; Volume 5.

42. Gayen, A.; Pourghasemi, H.R.; Saha, S.; Keesstra, S.; Bai, S. Gully erosion susceptibility assessment and management of hazard-prone areas in India using different machine learning algorithms. Sci. Total Environ. 2019, 668, 124-138. [CrossRef] [PubMed]

43. Hong, H.; Liu, J.; Zhu, A.-X.; Shahabi, H.; Pham, B.T.; Chen, W.; Pradhan, B.; Bui, D.T. A novel hybrid integration model using support vector machines and random subspace for weather-triggered landslide susceptibility assessment in the Wuning area (China). Environ. Earth Sci. 2017, 76, 652. [CrossRef]

44. Tehrany, M.S.; Pradhan, B.; Mansor, S.; Ahmad, N. Flood susceptibility assessment using GIS-based support vector machine model with different kernel types. Catena 2015, 125, 91-101. [CrossRef]

45. Mountrakis, G.; Im, J.; Ogole, C. Support vector machines in remote sensing: A review. ISPRS J. Photogramm. Remote Sens. 2011, 66, 247-259. [CrossRef]

46. Vapnik, V.N. The Nature of Statistical Learning Theory; Springer Science \& Business Media: Berlin, Germany, 1995.

47. Abedini, M.; Ghasemian, B.; Shirzadi, A.; Bui, D.T. A comparative study of support vector machine and logistic model tree classifiers for shallow landslide susceptibility modeling. Environ. Earth Sci. 2019, 78, 560. [CrossRef]

48. Yao, X.; Tham, L.G.; Dai, F.C. Landslide susceptibility mapping based on support vector machine: A case study on natural slopes of Hong Kong, China. Geomorphology 2008, 101, 572-582. [CrossRef]

49. Naghibi, S.A.; Moghaddam, D.D.; Kalantar, B.; Pradhan, B.; Kisi, O. A comparative assessment of GIS-based data mining models and a novel ensemble model in groundwater well potential mapping. J. Hydrol. 2017, 548, 471-483. [CrossRef]

50. Pradhan, B. A comparative study on the predictive ability of the decision tree, support vector machine and neuro-fuzzy models in landslide susceptibility mapping using GIS. Comput. Geosci. 2013, 51, 350-365. [CrossRef]

51. Kavzoglu, T.; Colkesen, I. A kernel functions analysis for support vector machines for land cover classification. Int. J. Appl. Earth Obs. Geoinf. 2009, 11, 352-359. [CrossRef]

52. Haykin, S. Neural Networks: A Comprehensive Foundation, 2nd ed.; Prentice Hall Inc.: Upper Saddle River, NJ, USA, 1999.

53. Cherkassky, V.; Krasnopolsky, V.; Solomatine, D.P.; Valdes, J. Computational intelligence in earth sciences and environmental applications: Issues and challenges. Neural Netw. 2006, 19, 113-121. [CrossRef]

54. Saha, A.K.; Gupta, R.P.; Arora, M.K. GIS-based landslide hazard zonation in the Bhagirathi (Ganga) valley, Himalayas. Int. J. Remote Sens. 2002, 23, 357-369. [CrossRef]

55. Kawabata, D.; Bandibas, J. Landslide susceptibility mapping using geological data, a DEM from ASTER images and an Artificial Neural Network (ANN). Geomorphology 2009, 113, 97-109. [CrossRef]

56. Kosko, B. Neural Networks and Fuzzy Systems: A Dynamical Systems Approach to Machine Intelligence; Prentice-Hall Inc.: Upper Saddle River, NJ, USA, 1992.

57. Mandal, S.; Mondal, S. Machine Learning Models and Spatial Distribution of Landslide Susceptibility. In Geoinformatics and Modelling of Landslide Susceptibility and Risk; Springer: Cham Switzerland, 2019; pp. 165-175.

58. Falaschi, F.; Giacomelli, F.; Federici, P.R.; Puccinelli, A.; Avanzi, G.; Pochini, A.; Ribolini, A. Logistic regression versus artificial neural networks: Landslide susceptibility evaluation in a sample area of the Serchio River valley, Italy. Nat. Hazards 2009, 50, 551-569. [CrossRef]

59. Chen, W.; Pourghasemi, H.R.; Zhao, Z. A GIS-based comparative study of Dempster-Shafer, logistic regression and artificial neural network models for landslide susceptibility mapping. Geocarto Int. 2017, 32, 367-385. [CrossRef]

60. Kim, P. Matlab deep learning. Mach. Learn. Neural Netw. Artif. Intell. 2017, 130, 21.

61. Lewis, N.D.C. Deep Learning Made Easy with R: A Gentle Introduction for Data Science. Advances in Swarm Intelligence. In Proceedings of the 11th International Conference, ICSI (AusCov), Belgrade, Serbia, 14-20 July 2020.

62. Kennedy, J.; Eberhart, R.C.; Shi, Y. The particle swarm. Swarm Intell. 2001, 287-325.

63. Kennedy, J.; Eberhart, R. Particle swarm optimization. In Proceedings of the ICNN'95-International Conference on Neural Networks, Perth, WA, Australia, 27 November-1 December 1995; Volume 4, pp. 1942-1948. 
64. Clerc, M.; Kennedy, J. The particle swarm-explosion, stability, and convergence in a multidimensional complex space. IEEE Trans. Evol. Comput. 2002, 6, 58-73. [CrossRef]

65. Olsson, A.E. Particle Swarm Optimization: Theory, Techniques and Applications; Nova Science Publishers, Inc.: Hauppauge, NY, USA, 2010.

66. Frattini, P.; Crosta, G.; Carrara, A. Techniques for evaluating the performance of landslide susceptibility models. Eng. Geol. 2010, 111, 62-72. [CrossRef]

67. Yesilnacar, E.; Topal, T. Landslide susceptibility mapping: A comparison of logistic regression and neural networks methods in a medium scale study, Hendek region (Turkey). Eng. Geol. 2005, 79, 251-266. [CrossRef]

68. Biot, Y.; Blaikie, P.M.; Jackson, C.; Palmer-Jones, R. Rethinking Research on Land Degradation in Developing Countries; The World Bank: Washington, DC, USA, 1995.

69. Sirviö, T.; Rebeiro-Hargrave, A.; Pellikka, P. Geoinformation in gully erosion studies in the Taita Hills, SE-Kenya, preliminary results. In Proceedings of the 5th AARSE conference (African Association of Remote Sensing of the Environment), Nairobi, Kenya, 7-22 October 2004; pp. 18-21.

70. Dotterweich, M.; Rodzik, J.; Zgłobicki, W.; Schmitt, A.; Schmidtchen, G.; Bork, H.-R. High resolution gully erosion and sedimentation processes, and land use changes since the Bronze Age and future trajectories in the Kazimierz Dolny area (Nałeczów Plateau, SE-Poland). Catena 2012, 95, 50-62. [CrossRef]

71. Pal, S.C.; Chakrabortty, R. Modeling of water induced surface soil erosion and the potential risk zone prediction in a sub-tropical watershed of Eastern India. Model. Earth Syst. Environ. 2019, 5, 369-393. [CrossRef]

72. Chakrabortty, R.; Pal, S.C.; Chowdhuri, I.; Malik, S.; Das, B. Assessing the Importance of Static and Dynamic Causative Factors on Erosion Potentiality Using SWAT, EBF with Uncertainty and Plausibility, Logistic Regression and Novel Ensemble Model in a Sub-tropical Environment. J. Indian Soc. Remote Sens. 2020, 1-25. [CrossRef]

73. Pal, S.C.; Chakrabortty, R. Simulating the impact of climate change on soil erosion in sub-tropical monsoon dominated watershed based on RUSLE, SCS runoff and MIROC5 climatic model. Adv. Sp. Res. 2019, 64, 352-377. [CrossRef]

74. Borrelli, P.; Robinson, D.A.; Fleischer, L.R.; Lugato, E.; Ballabio, C.; Alewell, C.; Meusburger, K.; Modugno, S.; Schütt, B.; Ferro, V.; et al. An assessment of the global impact of 21st century land use change on soil erosion. Nat. Commun. 2017, 8, 2013. [CrossRef]

75. Peng, T.; Wang, S. Effects of land use, land cover and rainfall regimes on the surface runoff and soil loss on karst slopes in southwest China. Catena 2012, 90, 53-62. [CrossRef]

76. Arabameri, A.; Pradhan, B.; Pourghasemi, H.R.; Rezaei, K.; Kerle, N. Spatial modelling of gully erosion using GIS and R programing: A comparison among three data mining algorithms. Appl. Sci. 2018, 8, 1369. [CrossRef]

(C) 2020 by the authors. Licensee MDPI, Basel, Switzerland. This article is an open access article distributed under the terms and conditions of the Creative Commons Attribution (CC BY) license (http://creativecommons.org/licenses/by/4.0/). 